\author{
REREm \\ OCT 319935 \\ OST
}

\title{
PHASE ONE CONTAMINATION MIGRATION TESTING OF THE DOUBLE-LID BAGLESS POSTING SYSTEM
}
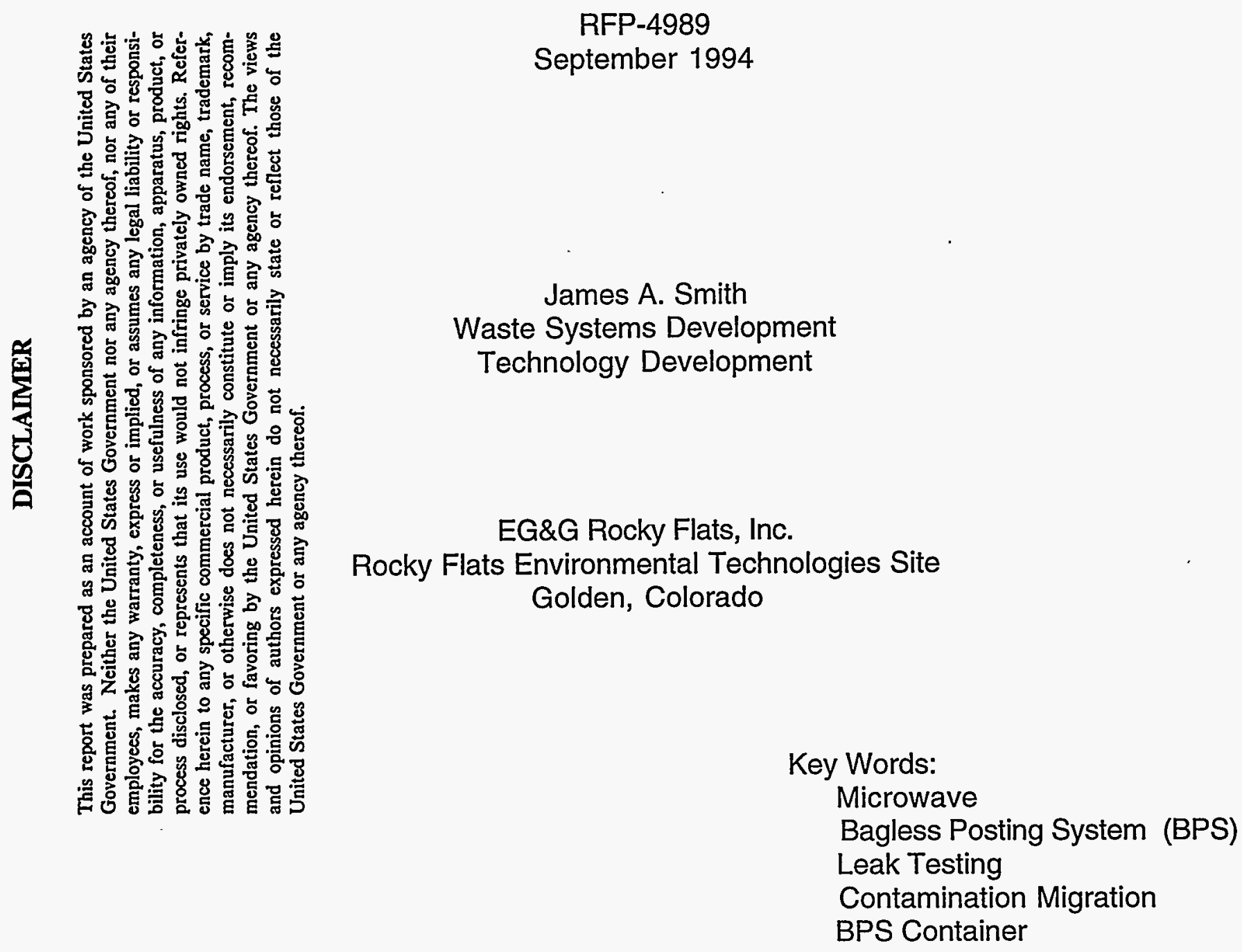
Table of Contents

Table of contents

i

List of Figures

ii

Purpose

1

Background

1

Procedure

Leak Rate

Container

1

$\frac{1}{5}$

Results and Discussions

Leak Rate

Container

Modifications

5

7

7

Conclusions

Recommendations 


\section{List of Figures}

Figure 1: Equipment Assembly 2

Figure 2: Upper and Lower Leak Chambers 3

Figure 3: Drath and Schrader Double Lid System 4

Figure 4: Container Assembly 6

Figure 5: Hempelmann Boot Gaskets 8 
PURPOSE

Determine the leak rate of the Drath \& Schrader double lid system during a simulated transfer operation.

\section{BACKGROUND}

The double lid system built by Drath \& Schrader uses a technique that has no bags during a transfer operation. The bags are typically used to contain a radiologically contaminated environment during routine bagout operations. This system has replaced the bags with a specially designed container. The container consist of a standard 55 gallon open headed drum, modified Hempelmann boot, inner lid and outer lid. Rocky Flats has designated this system the Bagless Posting System (BPS).

A demonstration BPS was setup to show how the system would perform in a glovebox environment with routine operations. The Microwave Solidification System (MSS) at Rocky Flats has currently been supporting development efforts. The three major areas of development are in leak rate for BPS (during transfer), container requirements and modifications to the existing equipment.

\section{PROCEDURE}

Leak rate:

Two leak chambers to enclose the BPS were constructed to evaluate the performance of the equipment. The leak chambers are large enough to enclose the BPS equipment in the upper chamber and container handling equipment in the lower chamber (see Figures 1 , 2 , and 3). Both chambers are required to have recirclation blower systems that control the design parameters for operating gloveboxes. The chambers have a High Efficiency Particulate Air (HEPA) filters for removal of particles during leak testing.

An initial test plan was provided by Robert Nininger of Environmental Protection Management Air Quality Branch at Rocky Flats. The test plan evaluated the performance of the leak chambers and transfer operations. All testing to date has been performed on non-contaminated environments. The plan required the atmosphere of the upper leak chamber be negative to the lower leak chamber. Background, infiltration, and decay tests were needed to quantify baseline operating parameters for the leak chambers. Once the operating parameters were known, the leak rate coefficient for the BPS apparatus (installed between the leak chambers) was evaluated by cycling the BPS through several opening and closing sequences. Contamination migration was determined by measuring a salt aerosol distribution in the upper and lower chambers. The complete test plan is included in Appendix A. 


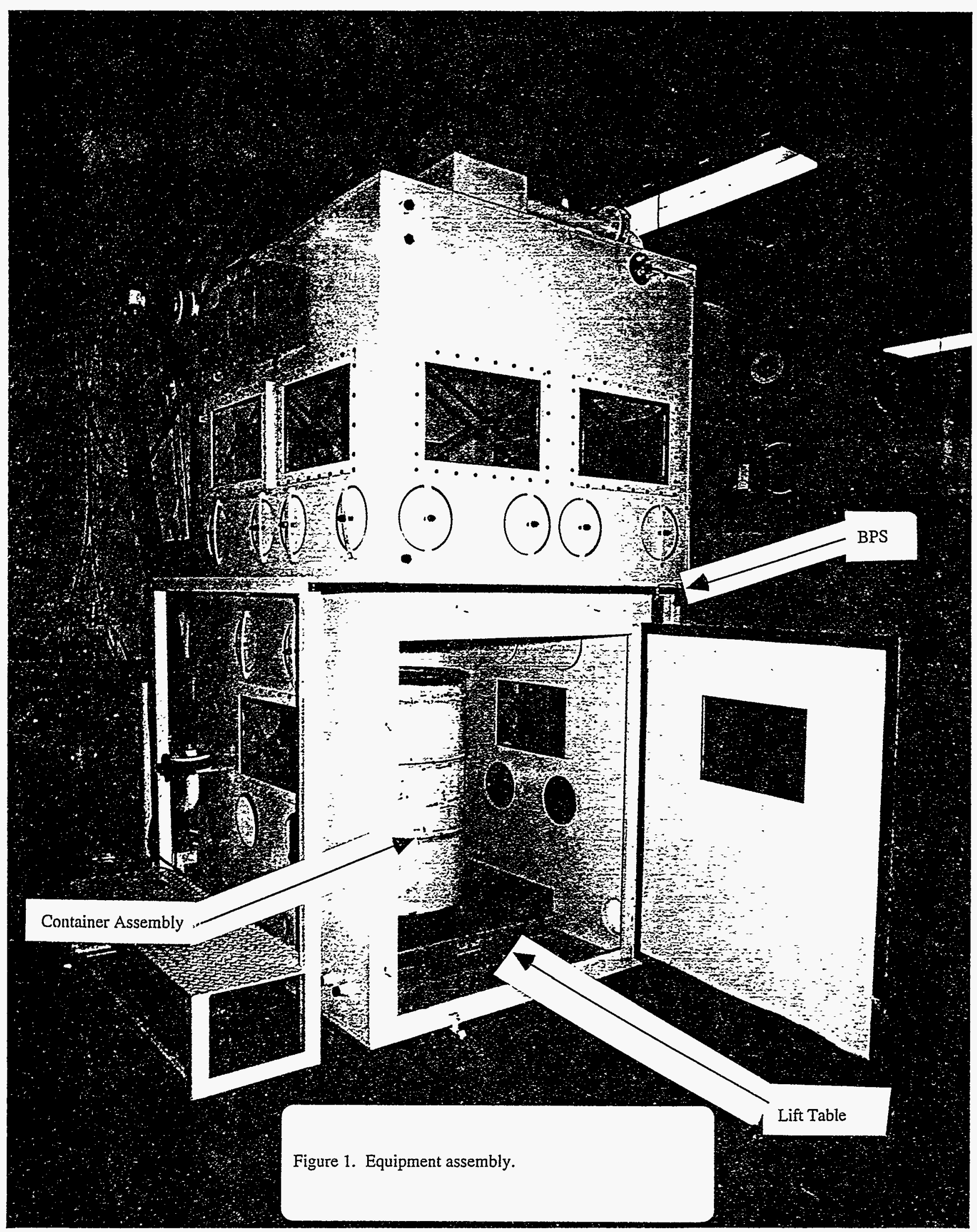




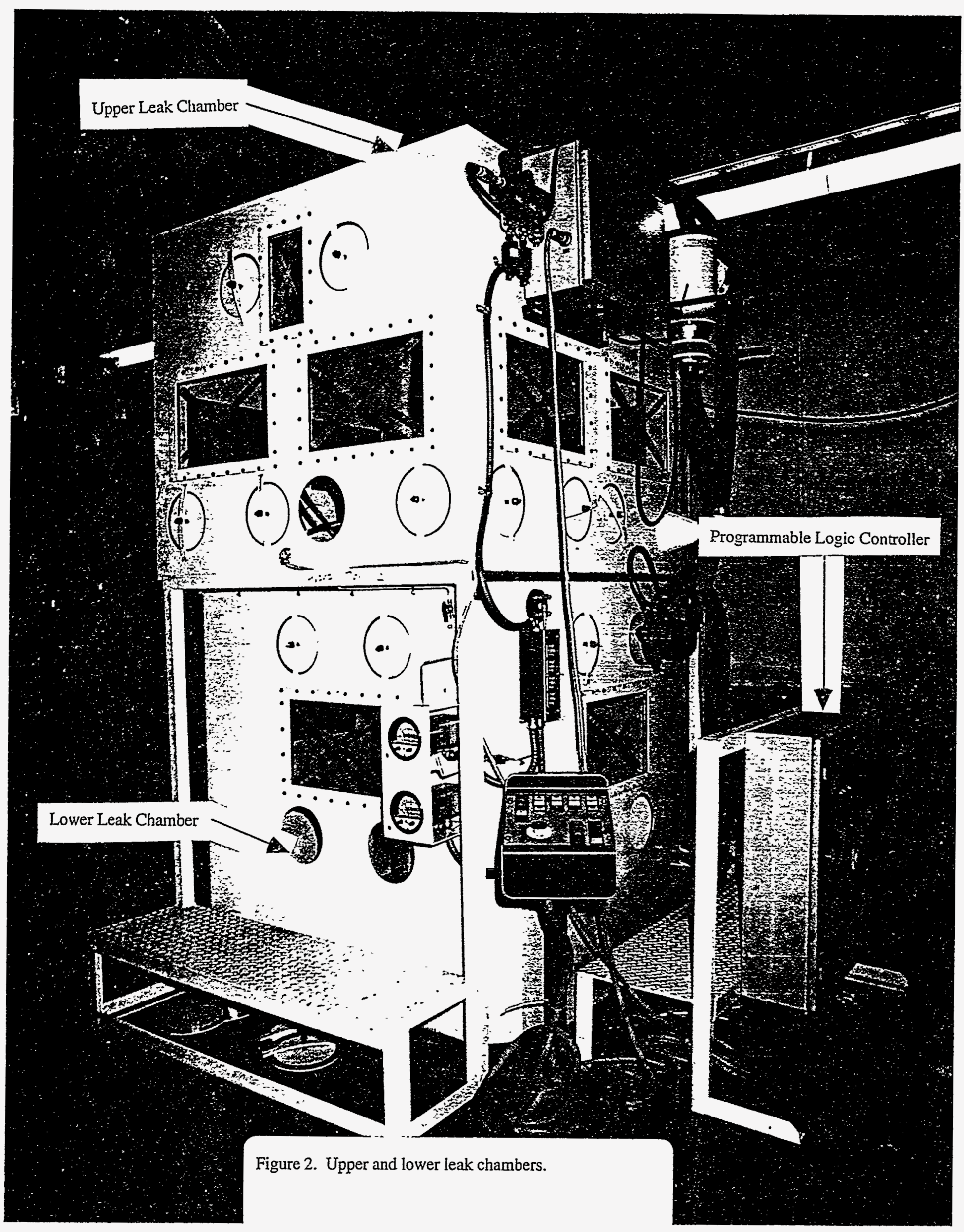


(3)

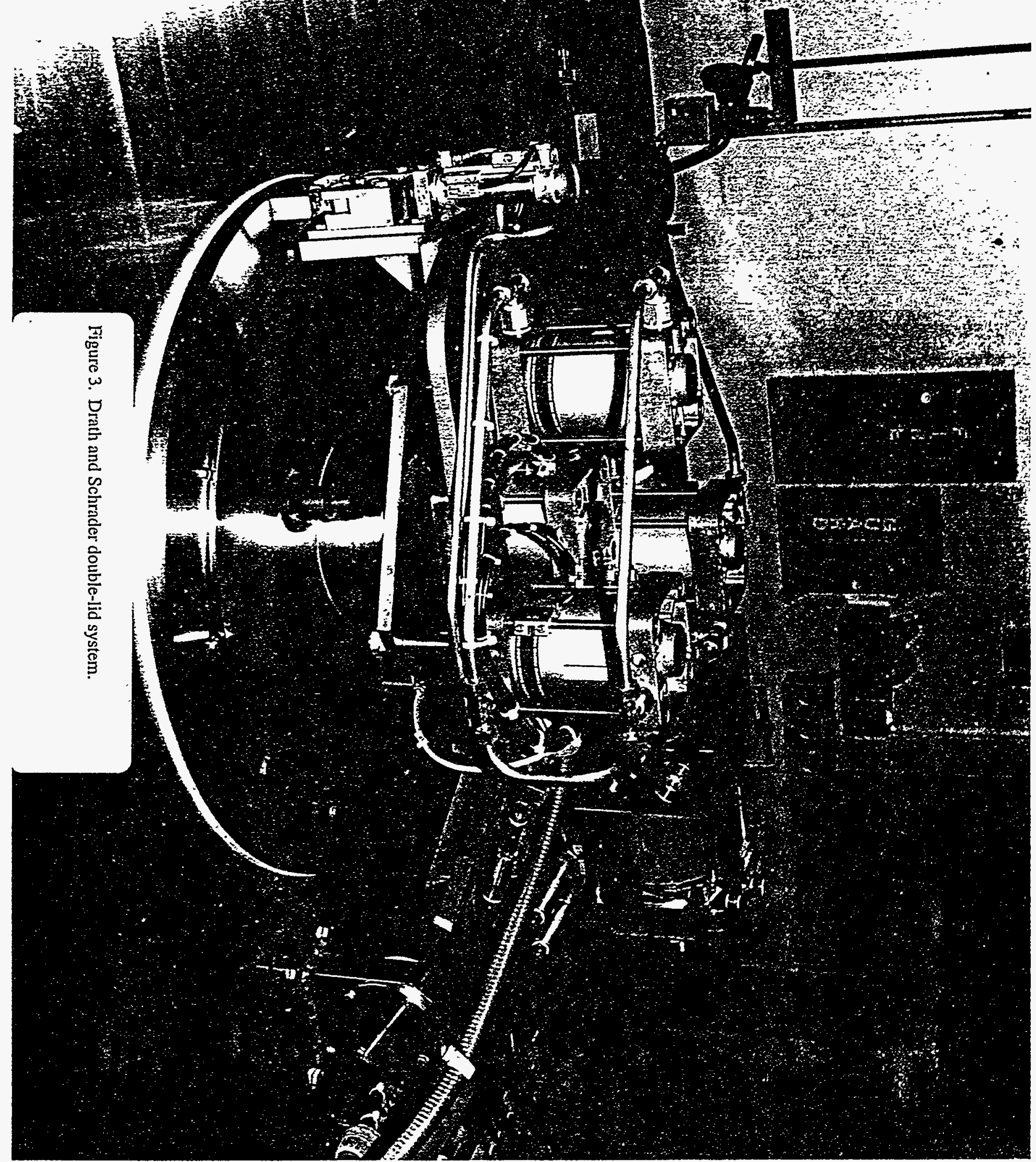




\section{Container:}

The original concept of the shipping container was developed by Drath \& Schrader GmbH. incorporating requirements from the plant standards at Rocky Flats. The original container from Drath \& Schrader used a standard 55 gallon 17C open headed drum (RFP SX200), Hempelmann boot (gasket), inner 200 liter simple Iid, and outer over lid (see Figure 4). The shipping package is assembled using the above components. The original Hempelmann boot did not meet the requirement for a seal tight container set forth in Title 49173.412 .

Different lots of manufactured drums were evaluated at Rocky Flats for dimensional tolerances. The plant standard $5 X-200$ specifically puts tolerances on the container in section 2.2. The actual dimension critical to this assembly is the inside diameter of the drum. Measurements were taken from 5 different lots with 2 samples from each lot.

\section{RESULTS \& DISCUSSIONS}

Leak Rate:

Several series of leak tests were performed using the test setup describe in Appendix A. Baseline operating parameters for the leak chambers and counting equipment were defined after running the system for several cycles. These parameters included how fast the chambers were able to achieve a stable background particle count, the infiltration rate of outside air, and particle size distribution. The complete data report for all of the tests is contained in Appendix A.

A stable background particle count (0.3-0.5 microns) of $2000-2500$ particles per minute was typically achieved in 30 minutes. This rate is dependent upon the cleanness and size of the leak chamber. Infiltration of clean, outside room air was noticeable when the pressure of the leak chamber was equal to the room. This typically happened within 5 minutes of shutting down the recirculating blower and resulted in a reduced particle count. Particle distribution can be seen in the Appendix B of the data report. The particles were non-uniform from series to series. Condensation and poor mixing affected the sensitivity of the results.

During testing the lift mechanism constantly drifted down thus allowing a inconsistent seal pressure. This was caused by a drift in the hydraulic cylinder that was part of the commercial lift table. This problem is noted in the data report. This problem caused the leak rate to vary from series to series. During the third series, the lift table was locked in place to avoid drift. This resulted in virtual elimination in contamination migration across the seal. 


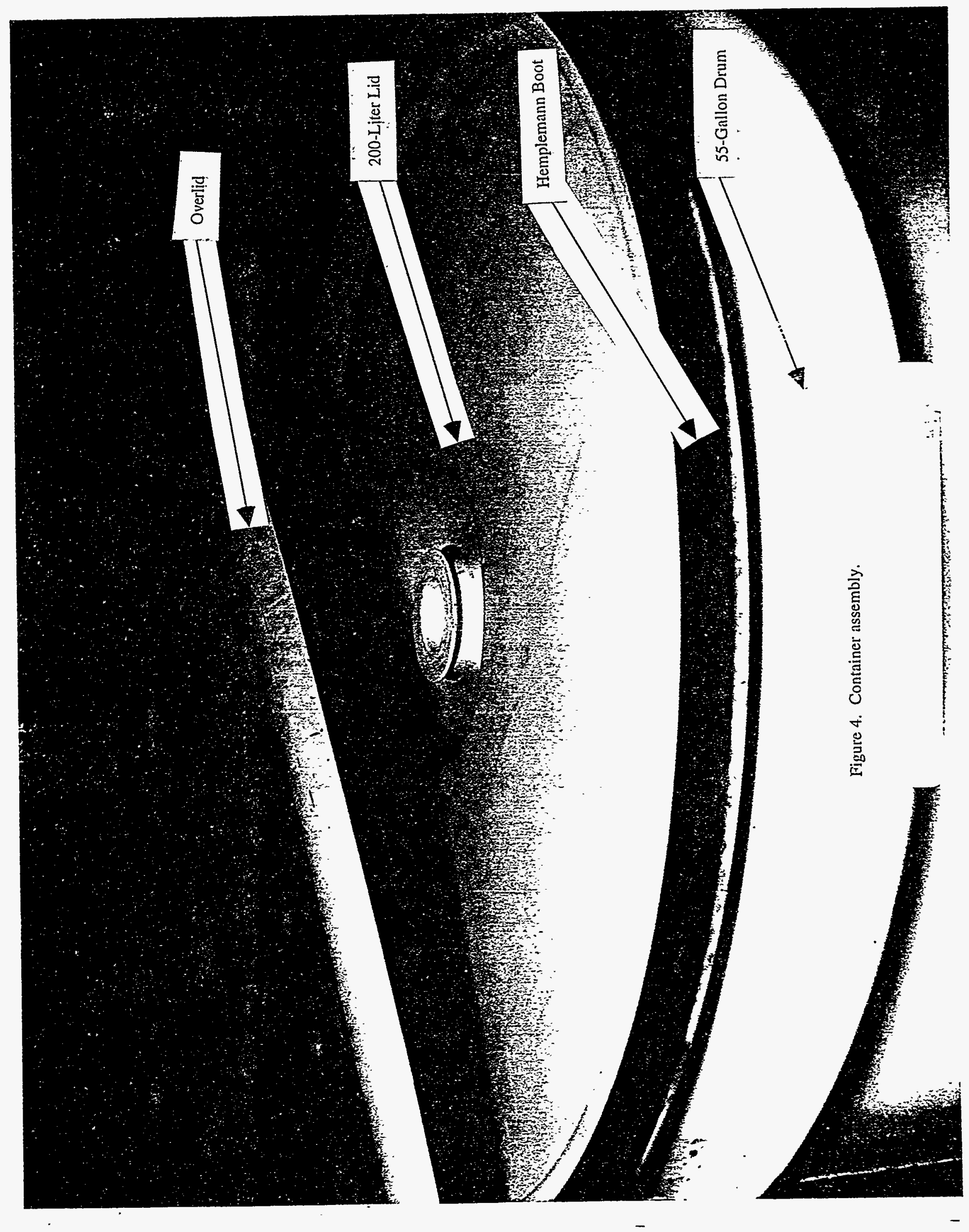


Container:

Dimensional data from the five lots of drums are summarized in Table 1. The overall trend for the inside diameter on the 55 gallon drum indicates that within the lot the tolerance fell within the requirements set by the standard (RFP $S X-200$ ). The problem came when different lots are compared. There is no tolerance call out between lots in the standard. This causes a problem when the gasket relies on the inside diameter of the drum to adequately seal the simple lid in position.

After a inside diameter for the drum was determined from several different lots, the Hempelmann boot gasket was redesigned. The gasket was redesigned because it was easier to change than the 55 gallon drums or the 200 liter lids. The inner 200 liter lid was checked for tolerance on the inside diameter of the sealing area. These lids were found to be very accurately made and had only .015 inch difference between 10 lids taken at random.

$\begin{array}{llllll}\text { Lot } & \text { Seam } & 45^{\circ} & 90^{\circ} & 135^{\circ} & \text { AVG. } \\ \text { I } & 22.358 & 22.393 & 22.467 & 22.326 & 22.426 \\ \text { I } & 22.453 & 22.407 & 22.465 & 22.458 & 22.443 \\ \text { B } & 22.461 & 22.353 & 22.439 & 22.523 & 22.488 \\ \text { B } & 22.458 & 22.398 & 22.433 & 22.477 & 22.467 \\ \text { J } & 22.510 & 22.329 & 22.428 & 22.506 & 22.499 \\ \text { J } & 22.543 & 22.390 & 22.397 & 22.454 & 22.517 \\ \text { J } & 22.490 & 22.432 & 22.381 & 22.400 & 22.485 \\ \text { J } & 22.537 & 22.459 & 22.415 & 22.429 & 22.521 \\ \text { M } & 22.465 & 22.421 & 22.423 & 22.440 & 22.458 \\ \text { M } & 22.460 & 22.424 & 22.422 & 22.467 & 22.438 \\ \text { M } & 22.460 & 22.432 & 22.428 & 22.445 & 22.460 \\ \text { N } & 22.480 & 22.394 & 22.393 & 22.457 & 22.488 \\ \text { N } & 22.467 & 22.409 & 22.430 & 22.478 & 22.462\end{array}$

Table 1. Inside diameter of $17 \mathrm{C} 55$ gallon open headed drun at top

Modifications:

Modifications to the actual commercial equipment from Drath \& Schrader have been minimal. Two areas have been modified to enhance the sealing capabilities of the system. The Hempelmann boot was modified to provide a tight seal between the drum and the inner 200 liter lid. The overall cross section of the gasket was increased to take up the gap between the drum and inner 200 liter lid. Figure 5 shows the original Hempelmann boot gasket on the left (void in cross section) and modified Hempelmann boot on the right. This modification now gives the container a seal tight arrangement for the lids.

The lift and position equipment have been redesigned to provide 


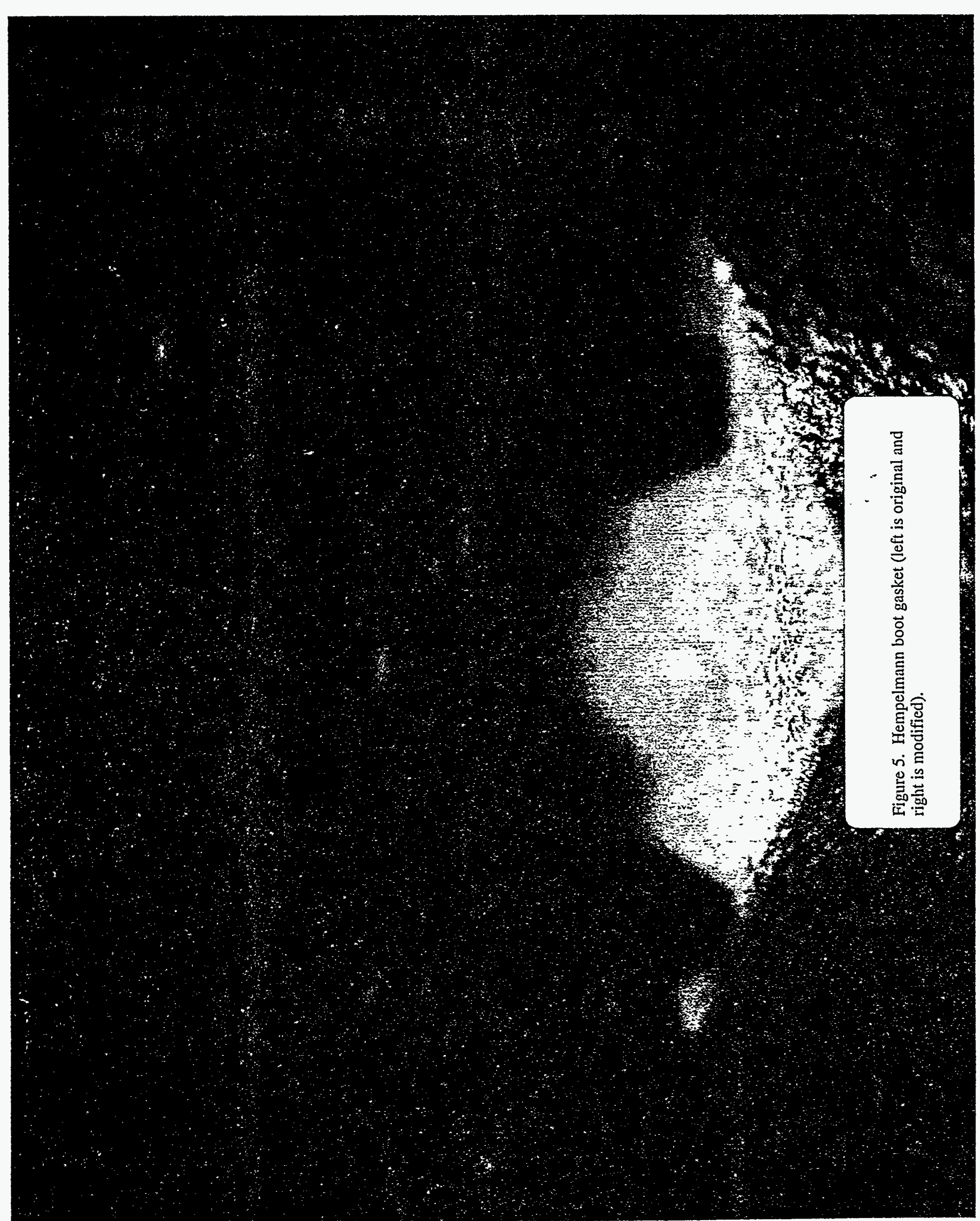


positive placement and sealing of the drum to the BPS sealing surface.

Reliability Availability and Maintainability (RAM) analysis is used to identify any deficiencies of components and equipment before the system is installed into a glovebox type atmosphere. Preliminary RAM analysis has shown that only minor modification to the limit switch alignment and container positioning is required. During testing and operation of the BPS no major component failure for the equipment has occurred. The control system uses a Programmable Logic Controller (PIC) to operate the system. The PLC has a EPROM memory that can only be changed by the manufacturer. During testing and evaluation the capability to change the operating program is useful. This part of the system has been a nuance to deal with during operations.

Access ports and windows have been located on the leak chambers. These ports provide a basis to evaluate maintainability of the equipment during glovebox operations. Maintenance and adjustment made during operation have been completed easily though standard size openings and spacing.

\section{CONCLUSION}

The worst leak rate observed during testing of the Hempelmann boot gasket and equipment was $1.4 \%$. This leak rate represents the leak between the upper chamber and the lower chamber during a transfer cycle. The leak rate was below the detection limit after locking the lift table into position during the third series. Fixing the position of the drum and maintaining a constant seal pressure against the equipment showed that the design is capable of maintaining a tight seal during the transfer. These results indicate that maintaining as upward seal pressure is critical to redesign of a new lifting and position system.

The preliminary performance evaluation of the test container was completed in september 1993. This evaluation has been forwarded to the Traffic Department at Rocky Flats. The Traffic Department will then request that a docket be opened at Hanford for final Department of Transportation approval of the purposed container.

The original equipment and software for the BPS have not required any major changes. All of the original components have been cycled extensively through the series of testing and preliminary RAM analysis.

\section{RECOMMENDATIONS}

The next useful step in the evaluation of this project is to gain 
experience in a contaminated environment. Data from an installed system in a radiological area would give potential users the actual performance specification for the equipment and containment systems. This system would be valuable in an installation that requires routine bag out operations. In this application it would reduce material and labor costs. Additionally, the equipment can be used to repack problem containers and evaluate ongoing inventory or audit checks.

The lift mechanism has already be redesigned and will begin fabrication in first quarter FY 95. The new lift table consists of a system of screw jacks to provide positive placement. Additionally, the system will be able to locate the drum and monitor the upward sealing force of the container through the PLC. once the new lift table has been fabricated and installed, further leak testing of the system will be performed. This additional testing will follow the pattern of this test series and will incorporate the Air Quality recommendations contained in this report.

The finial recommendation is to review and modify plant standard sX-200 ensure uniform drum tolerances across manufacturing lots. 
Appendix A 
Data Report

\title{
PARTICLE LEAK TESTING OF THE \\ DOUBLE-LID BAGLESS POSTING SYSTEM
}

\author{
Robert C. Nininger \\ Environmental Protection Management \\ Air Quality Branch
}

EG\&G Rocky Flats, Inc.

Golden, CO

August 1994 
Introduction 1

1. Test Procedure 1

1.1 Description of Test Series 5

2. Results 8

2.1 Preliminary testing 7

2.2 First Test Series 7

2.3 Second Tesit Series 12

2.4 Third Test Series 19

3. Problems and other Observations 24

4. Summary 25

5. Recommendations 26

Appendix A - Test Plan for Bagless-Posting System Particle Leak Test

Appendix B - Particle Counting Data 


\section{List Of Figures}

Figure 1 Test chamber schematic 2

Figure 1a Air handling system 3

Figure 2 Cross section of Hempelmann Boot showing seal between drum and door closure mechanism 4

Figure 3 Outline of test sequence $\quad 6$

Figure 4 First test series 9

Figure 5 First test series, response prior to introduction of aerosol in upper chamber 10

Figure 6 Shows lower chamber response after opening transfer door 11

Figure 7 First test series, response after closing transfer door 13

Figure 8 First test series, final door closure 14

$\begin{array}{lll}\text { Figure } 9 \text { Second test series } & 15\end{array}$

Figure 10 Second test series prior to first transfer cycle 16

Figure 11 Second test series, transfer door open, pressure on drum seal low at point noted

17

Figure 12 Second test series, response following closure of transfer door 18

$\begin{array}{lll}\text { Figure } 13 \text { Third test series } & 20\end{array}$

Figure 14 Third test series: drum fixed, opening cycle 21

Figure 15 Shows greater population stability with fixed drum; compare with Figure 11, for example 22

Figure 16 Final cycle; continuing to demonstrate good population stability 23 


\section{PARTICLE LEAK TESTING \\ OF THE \\ DOUBLE-LID BAGLESS POSTING SYSTEM}

\section{Introduction}

Tests have been performed to characterize and quantify the potential leakage rates of small airborne particles between two test chambers separated by a pneumatically controlled door. These chambers constitute a test prototype of a "bagless posting system" for packing contaminated materials in a waste drum. The configuration simulates the geometry between two isolated chambers, the upper one containing an atmosphere having potentially radioactive airborne particles, and the lower one constituting a receiving area into which is placed a standard 55-gallon drum container to be loaded from the contaminated upper chamber without exposing the drum's outer surface or the surrounding air to the contamination. A pneumatically actuated door and a mechanically attachable drum lid are used to expose and isolate the interior of the shipping container. The drum is mounted on a vertically moveable platform and is raised against a sealing lip on the lower outer rim of the door surround during the material transfer. The test setup is shown schematically in Figures 1 and 1a. Drum seating is enhanced by fitting a neoprene ring, called a Hempelmann Boot (see Figure 2), over and inside the drum's open mouth. The drum is sealed after material transfer using a special "European" lid that fits snugly into the Boot. This lid must be used with the bagless posting system.

\section{Test Procedure}

Testing was performed in general accordance with the Test Plan attached to this document as Appendix $A$. The tests were designed to quantitatively assess changes in particle concentrations in one test chamber under conditions where the second chamber contained a higher concentration of aerosol particulate matter with a measured size distribution. Various changeable physical barriers were mounted between the two chambers, including a sealed door, a rubber gasketed drum and a sealed door, or only a rubber gasketed drum.

The test aerosol consisted of salt $(\mathrm{NaCl})$ particles introduced into the upper chamber from a polydisperse aerosol generator using an aqueous solution of the salt. Particle concentrations were measured in both the upper and lower chambers using a Climet Laser-based Particle Counter that is able to detect and count particles in six particle size ranges $(0.3-0.5,0.5-0.7$, $0.7-1.0,1.0-5.0,5.0-10.0$ and $>10.0$ micrometers $\left(10^{-6} \mathrm{~m}\right)$ optical diameter). 


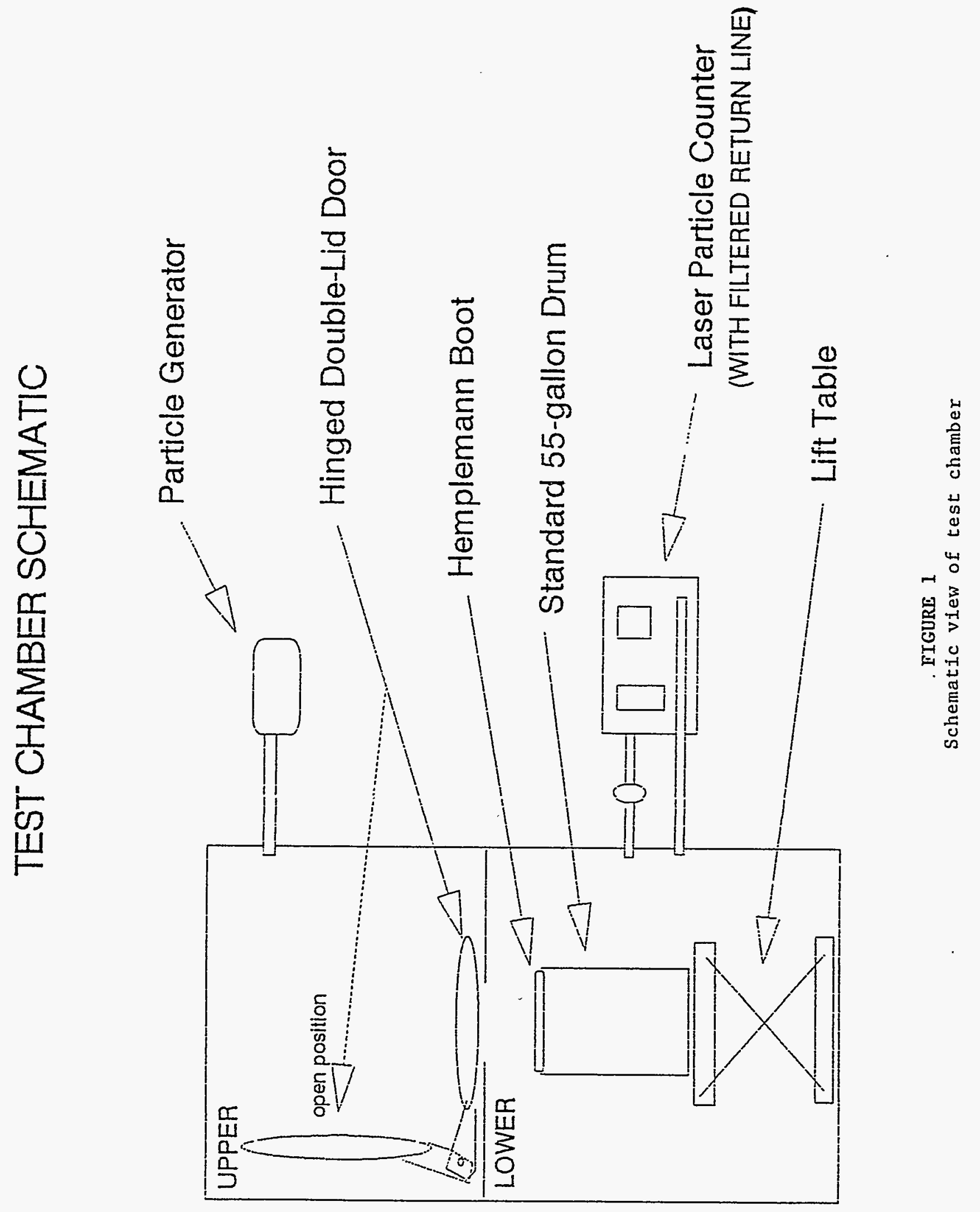




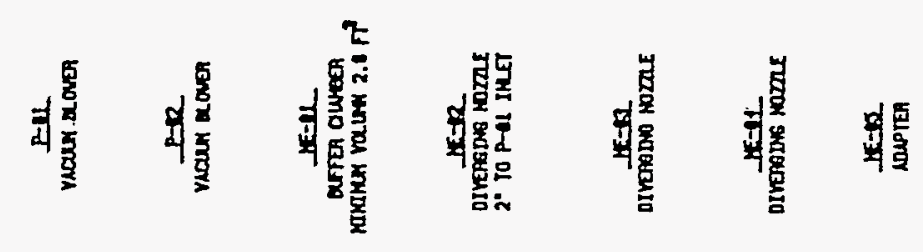

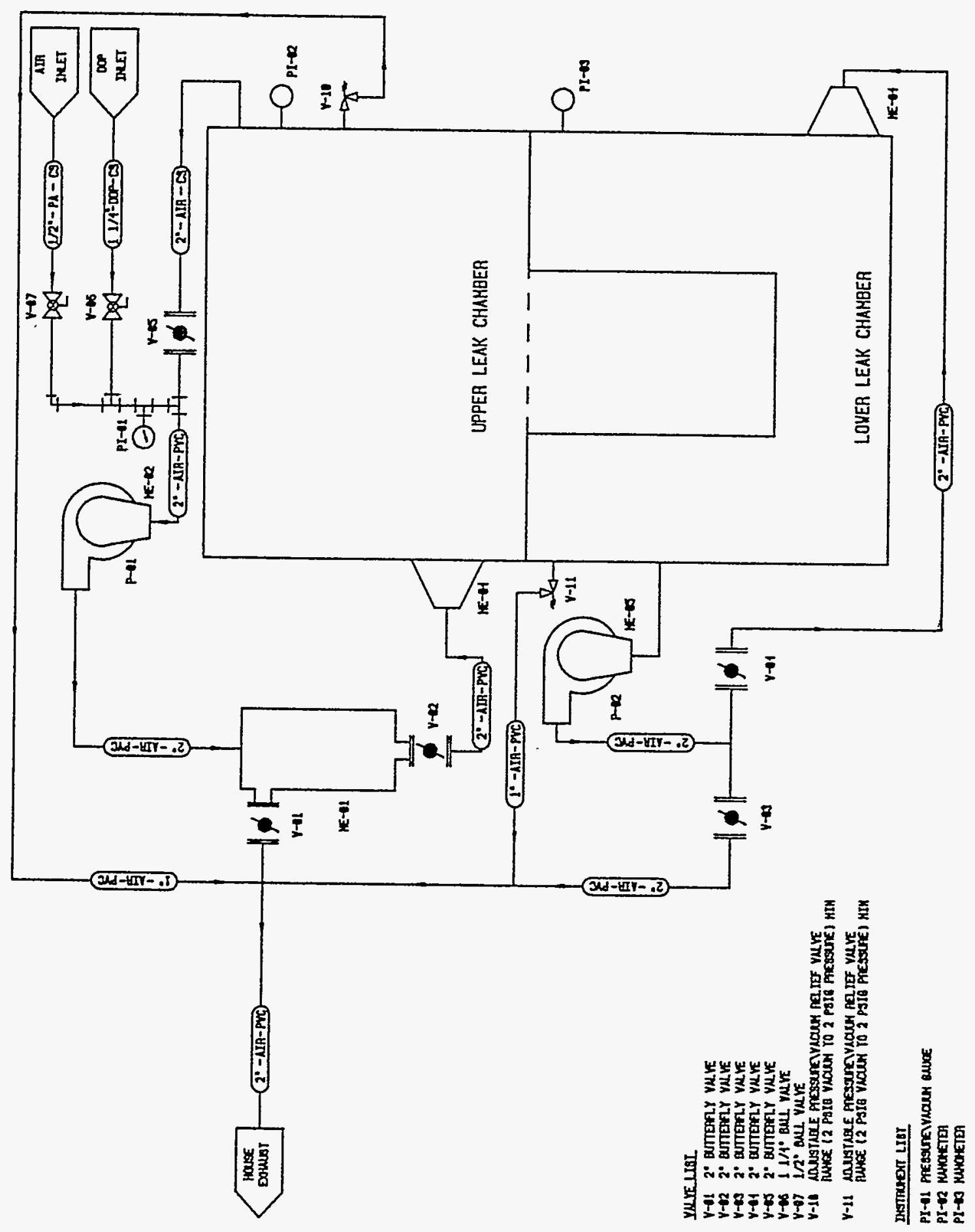

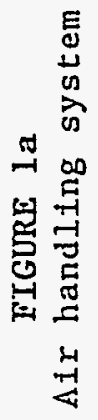




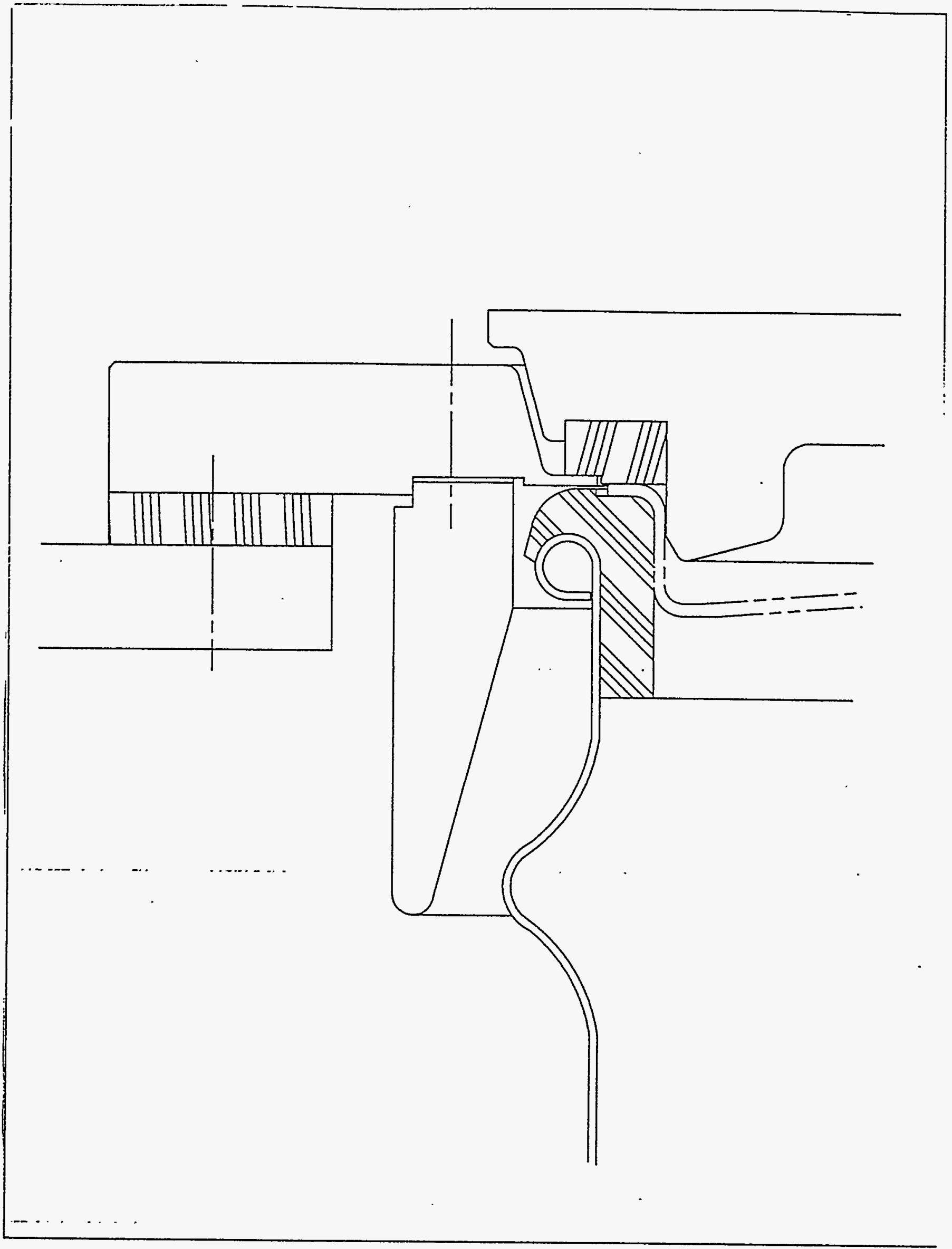

FIGURE 2

Cross section of Hempelmann Boot showing seal between drum and door closure mechanism 


\subsection{Description of Test Series}

The first and second test-series consisted of the measurement steps outlined below.

Figure 3 illustrates these steps schematically:

1. Air in the separately isolated lower and upper test chambers was filtered to remove ambient particulate matter that would interfere with the detection of changes in the test-particle concentrations that were to be measured. Filtering was performed using a blower recirculation system and a HEPA filter that could be selectively attached to one or both of the two test chambers. The particle concentrations that resulted from the filtration and equilibration of the remaining particles in the test chambers were measured and their changes were observed over time in order to establish a baseline particle concentration and size characterization.

2 - Aerosol was injected into the upper chamber, with the lower chamber still isolated by the sealed pneumatic door. A series of one minute observations ( 54 second sampling, 6 second printout) was continually performed both before and after the injection of particles in order to characterize changes in the lower chamber's particle concentration.

3. The sealed shipping drum was raised against the sealing surface around the circular door to the upper chamber. Measurements of particle concentration in the lower chamber were continued during this process and afterward so that changes in concentration could be associated with this operation.

4. With the shipping drum seated in place against the door's outer frame, the pneumatic door was raised, simultaneously opening the lid of the shipping drum and exposing the inside of the drum to the contents of the upper chamber. Measurements of particle concentration in the lower chamber were continued during this process and afterward to determine whether this operation caused any measurable changes in the particle concentrations in the lower test chamber.

5 - With the shipping drum still seated against the sealing flange around the door, the door was lowered and sealed, and the drum sealed by the specially fitted cover, returning the test configuration to that of step 3 above. Particle concentrations were measured in the lower chamber to again determine whether this operation caused changes in particle concentration in the lower chamber.

6 - The shipping drum was lowered away from the door's outer frame, returning the configuration to its original mode. Particle concentrations were again continually monitored.

7 - Steps $3,4,5$ and 6 were repeated to complete the test series. 


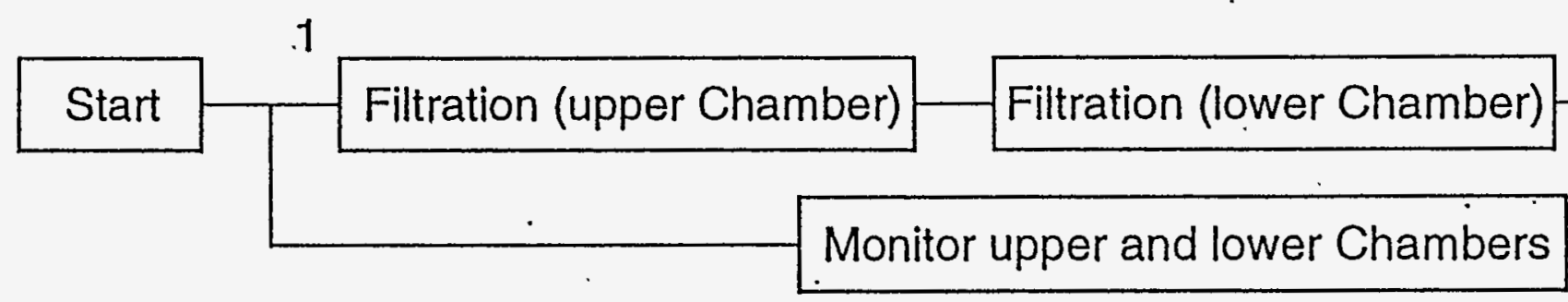

a

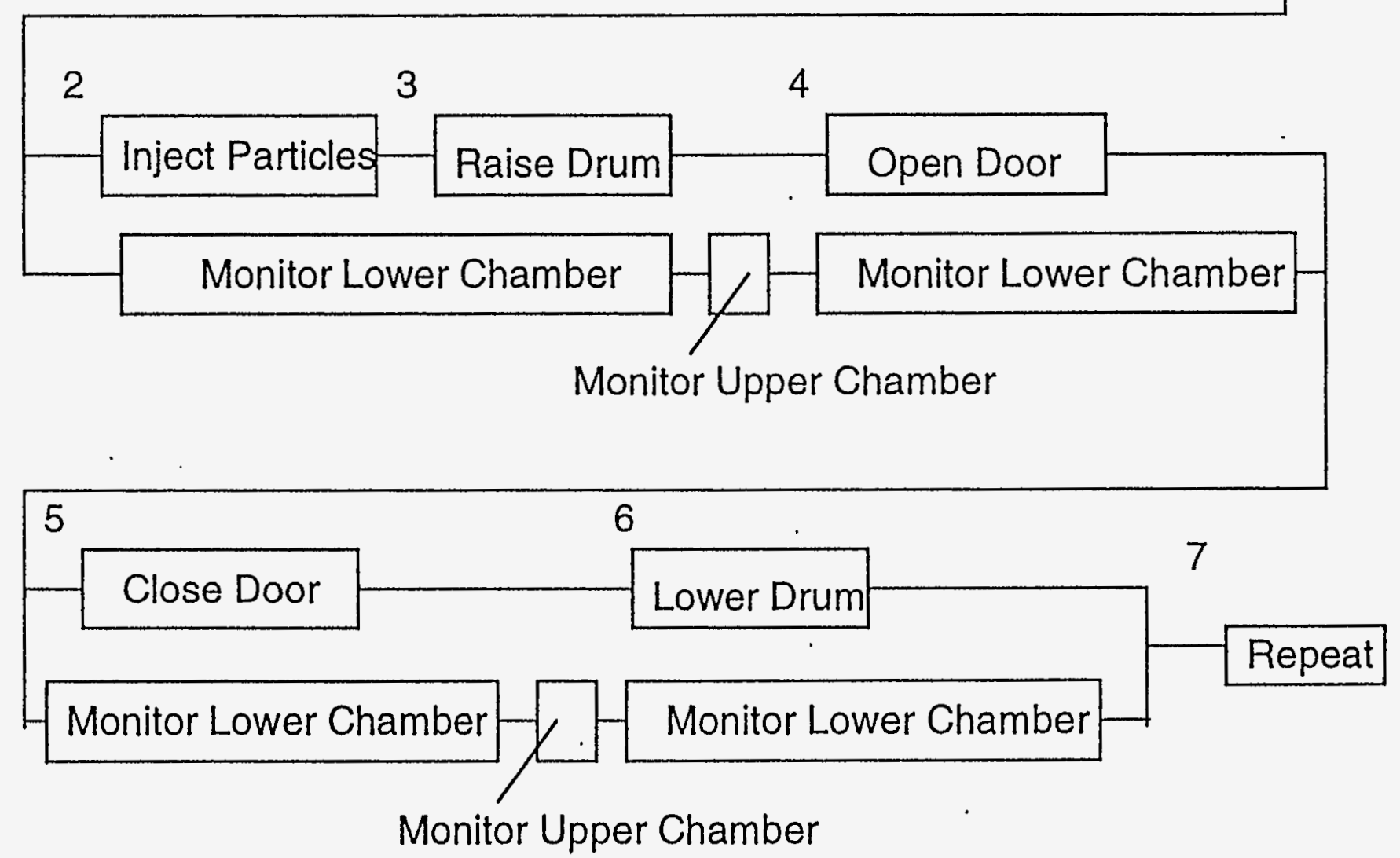

FIGURE 3

Outline of test sequence 
The third test series was a repeat of the first two with the exception that the drum was raised and fixed against the door seal prior to beginning the test series. This allowed only steps $1,2,4$ and 5 to be performed, with several repetitions of the door cycling procedure. The necessity of this testing procedure is discussed in detail under Section 3, Problems.

At various times during all three test series, the upper chamber's particle concentration was monitored briefly (several minutes each time) to quantify the concentration of the challenge aerosol. This measurement was necessary for later quantification of the leak rates. 
The results of the three tests are presented in this section, including both a qualitative interpretation and a limited quantitative interpretation of the data. The data from the three test series are presented as Appendix $B$.

\subsection{Preliminary testing}

During preliminary tests to characterize the behavior of the test chambers, very high particle counts were observed following a two day period when the freshly cleaned and prepared drum was positioned inside the lower test chamber. Comparison of the particle concentrations in the chambers with ambient concentrations in the room suggested that a source of particles existed either inside the closed lower test chamber or inside the drum that was housed inside the chamber. After careful examination of the system and considerable cleaning of interior surfaces, the source was traced to the adhesive material (Cosmaline) used to attach the Hempelmann Boot to the shipping container. This source was minimized by heating the ring and drum lip with a heat gun to more rapidly remove potential outgassing materials. The particle counts could then be maintained at levels low enough not to interfere with the testing. Leak testing was performed following these preparatory tests and activities.

\subsection{First Test Series}

Following preparatory testing, the first series of particle counts was performed in the lower transfer chamber of the bagless posting system. Figure 4 shows a time-series plot of the counts registered in the lower chamber during this series of tests. Annotations to the figure describe changes in the system configuration. The annotations indicate aerosol injected into the upper chamber (A), drum raised and seated on door lip (DR), transfer door opened (O), transfer door closed $(C)$, and drum lowered away from the door lip (DL). Particle size ranges are indicated in the legend at the bottom of each plot. Gaps in the time series (typically 4 to 6 minutes) correspond to periods when the particle counter was attached to the upper chamber in order to measure the challenge concentration of salt particles. Figures 5 through 8 show shorter periods of time in the test series and the resulting greater detail. These figures are used as reference in the discussion that follows.

Figure 5 shows the period during which no challenge aerosol was present in the top chamber, and the period when the drum remained stationary on its lift, without contact against the transfer door's sealing flange.

The sudden increase in particle count rate following the first opening of the transfer door, illustrated in Figure 6, suggests that seal integrity between the neoprene drum seal and the door lip is compromised. The rate of increase indicates a leak rate of approximately 15 particles per cubic meter per minute (550 particles/ft 3 -min in sizes ranging between 0.3 and 0.5 microns). This estimate includes compensation for possible particle loss due to deposition and filtration through the particle counter, based on the baseline data for the same size range. Only the smallest particle size range is quantified in these discussions; these particles would be expected to have the greatest leak potential of the size ranges measured. 


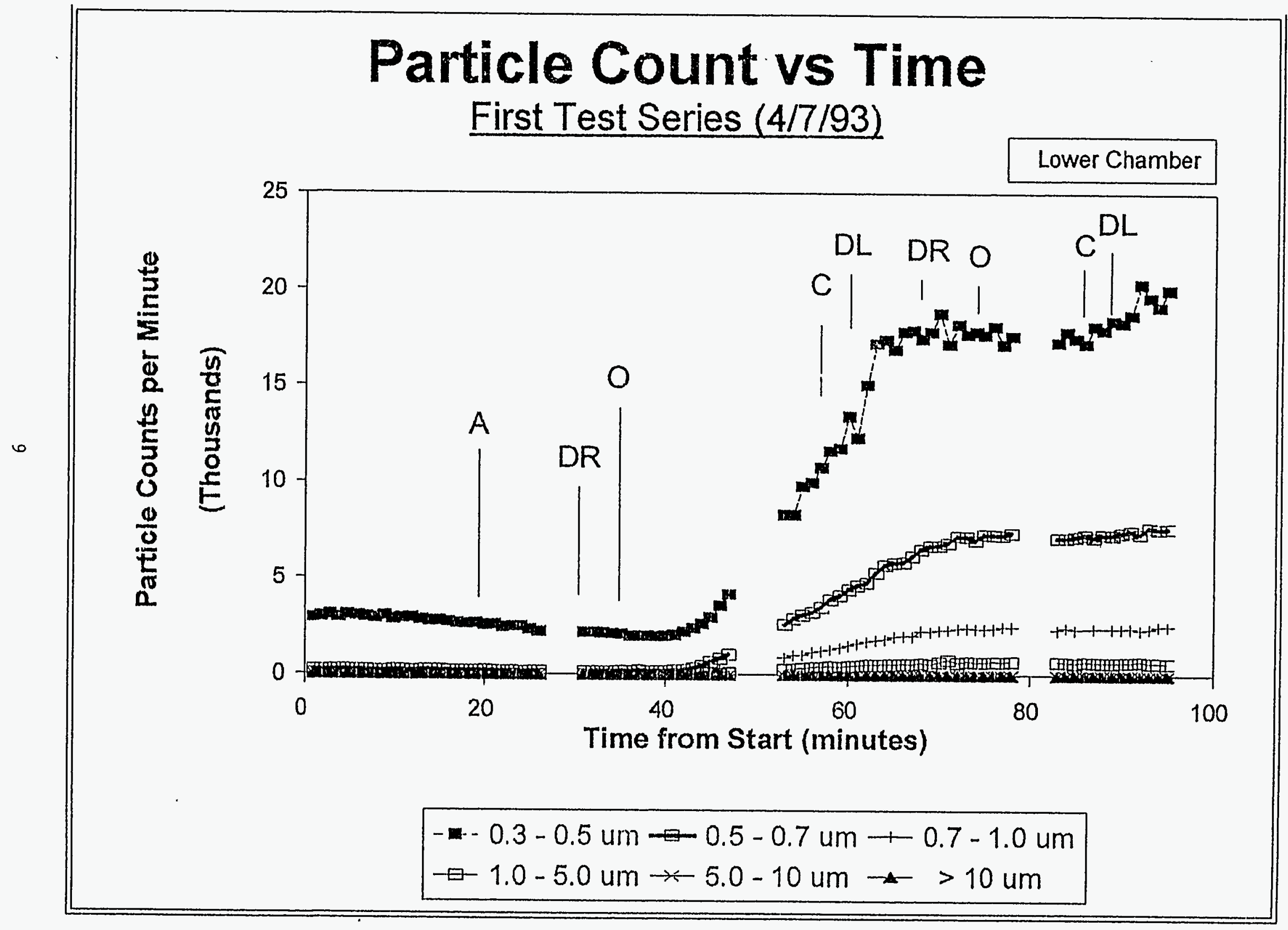

FIGURE 4. First Test Series (see text for annotation explanation) 


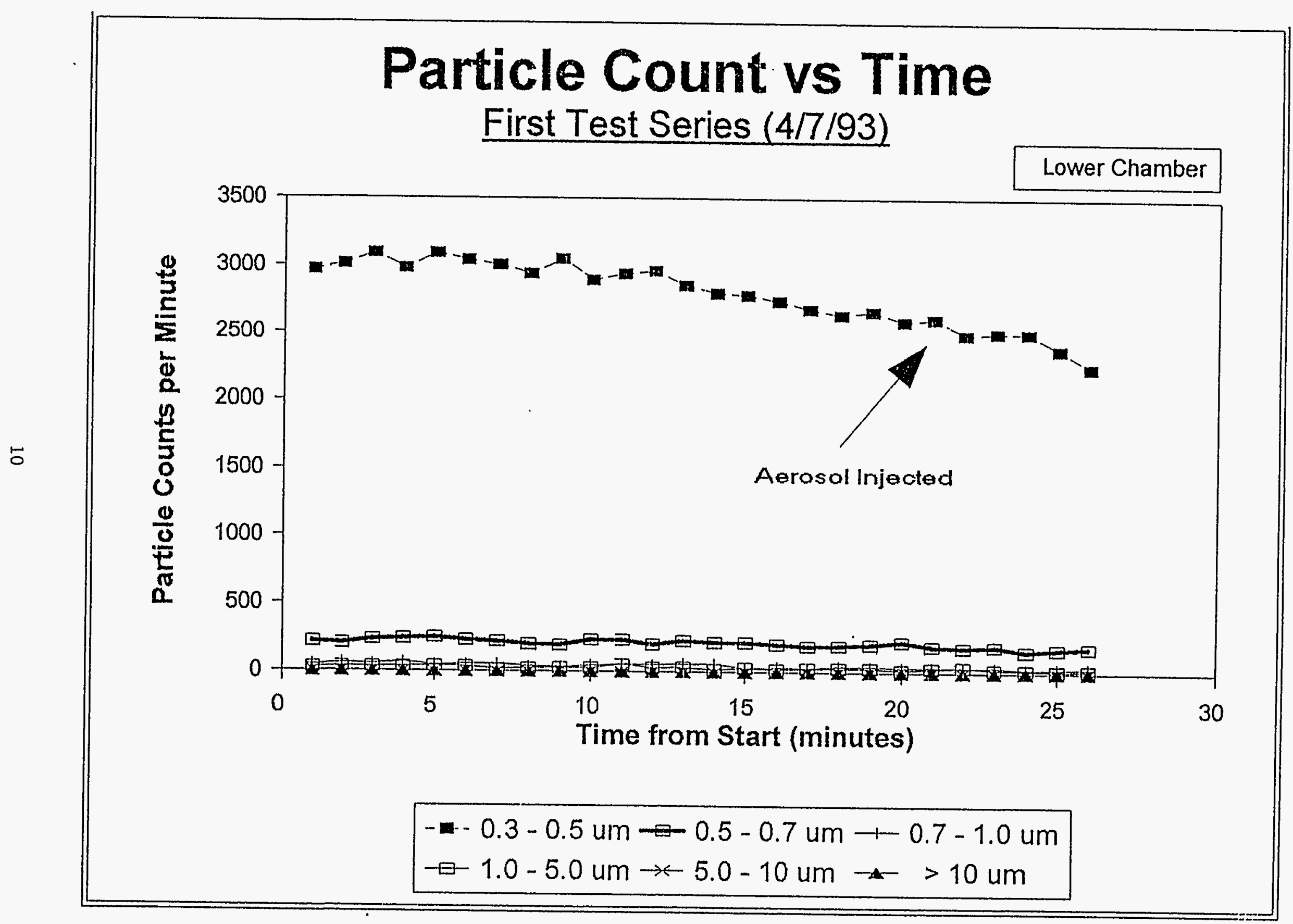

FGURE 5. First Test Series, Response Prior to Introduction of Aerosol in Upper Chamber. 


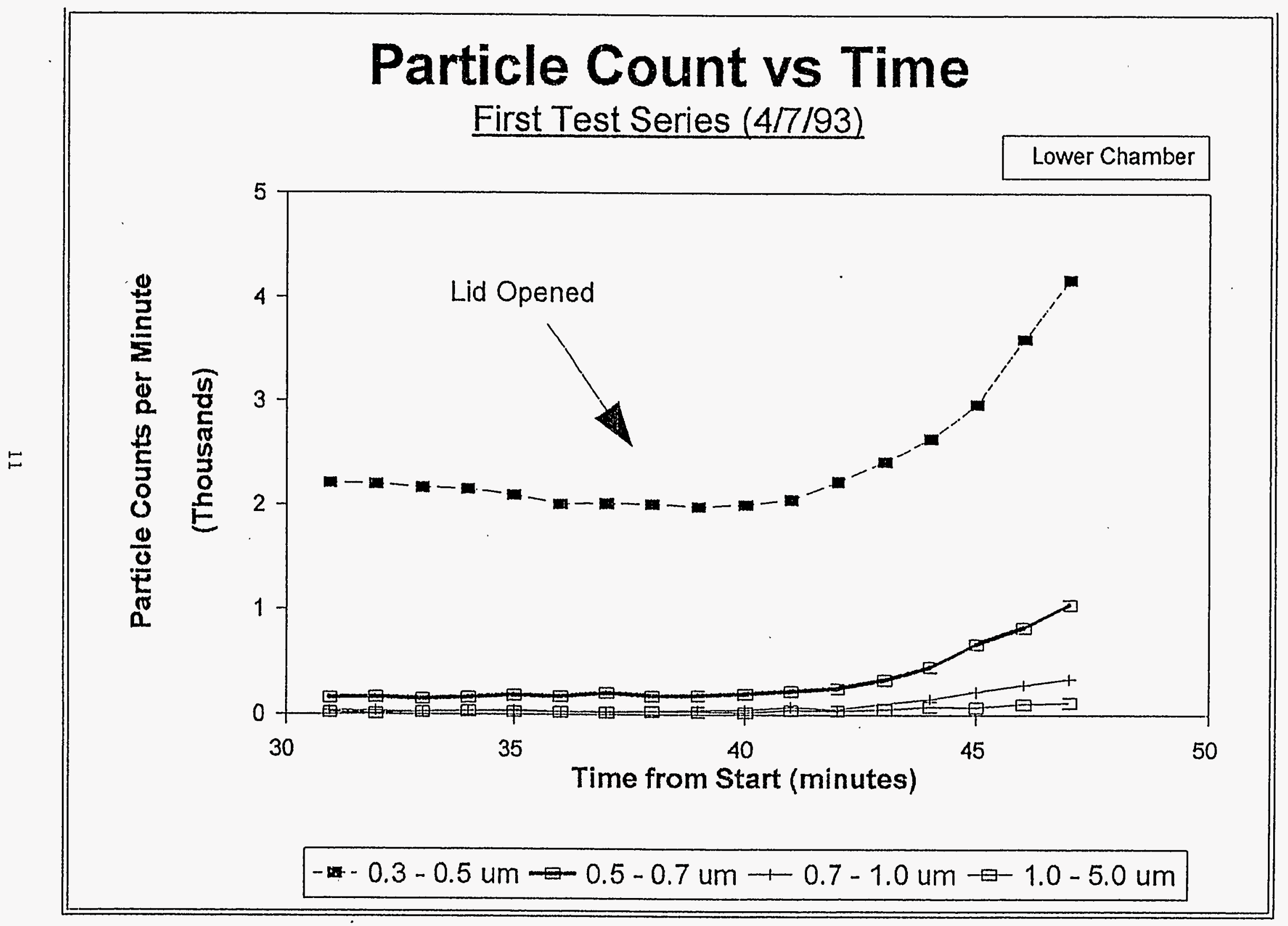

FIGURE 6. Figure shows low/er chamber response after opening transfer door. 
Measurements of particle concentration in the upper chamber indicate a concentration of around 2200 particles per cubic meter $(79,000$ particles/ft 3$)$ in the same particle size range. From these data the leak rate is estimated to be around 0.7 percent per minute of the upper (potentially contaminated) chamber's particles. 1

Closure of the transfer door results in a reduced rate of increase in particle concentration, as can be observed in Figure 7 following the annotation "drum lowered". Comparing the delay time between "lid open" and the observed increase in particle counts shown in Figure 6 with the time between "lid closed" and "drum lowered" annotations in Figure 7 suggests that the leak actually stopped when the transfer door was closed, and was not influenced by the drum's movement away from the transfer door's seat.

When the door was again opened, the count rate was not observed to increase significantly. This behavior is shown in Figures 7 and 8 . This behavior suggests that the drum seal against the transfer door's flange had good integrity during this second cycle. The leak rate during this test was small and not quantifiable.

Following this series of tests, the salt aerosol was cleaned from the two chambers using the HEPA filtration system and the apparatus was prepared for a second test series.

\subsection{Second Test Series}

Figure 9 shows a time-series plot of the entire second test series. This figure and the details of Figures 10 through 12 show similar characteristics to those of the first test series. Figure 10 shows the stable period prior to opening the transfer door, Figure 11 shows an increase in particle counts after the door is opened, and Figure 12 shows the delayed return to a stable count rate following closure of the transfer door. The note on Figure 11 indicating "load less than 90 pounds" indicates a counting cycle when the force between the drum and the door lip decreased significantly below the normal $300+$ pound range that was maintained manually throughout the tests. This resulted from the tendency of the lift to continuously drop during the tests, requiring the lift operator to increase the force. These "bumps" (load increases on the drum seal) were speculated to have contributed to the measured leak rate.

The estimated leak rate from the second test series was 1.4 percent per minute of the particles measured in the upper test chamber.

Explaining this measure of leak rate; if the upper chamber were contaminated with 100,000 particles per cubic foot and the particle count in the lower chamber were increasing at a rate of 100 particles per cubic foot per minute, without loss, the leak rate would be expressed as 0.1 percent per minute. 


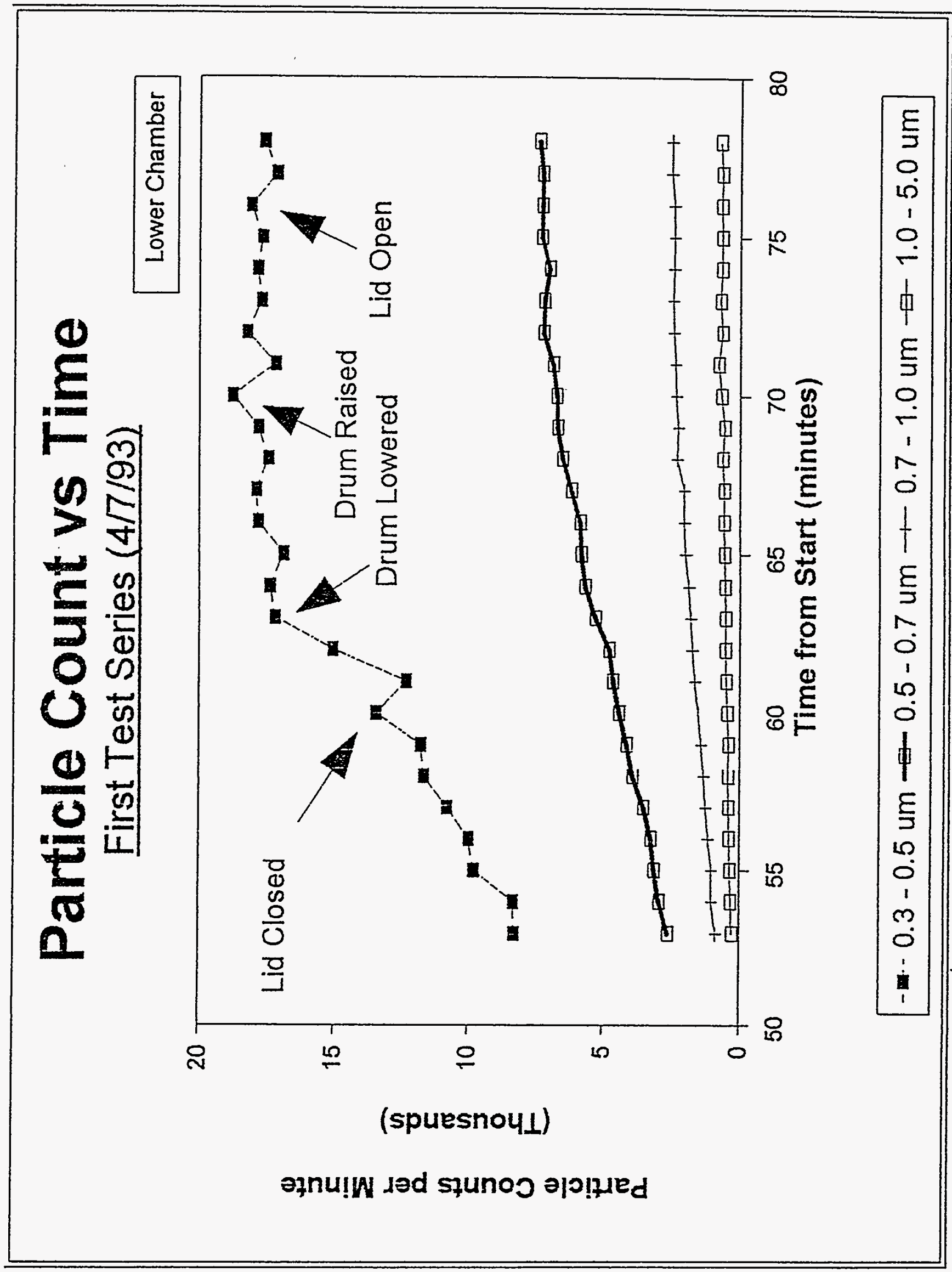




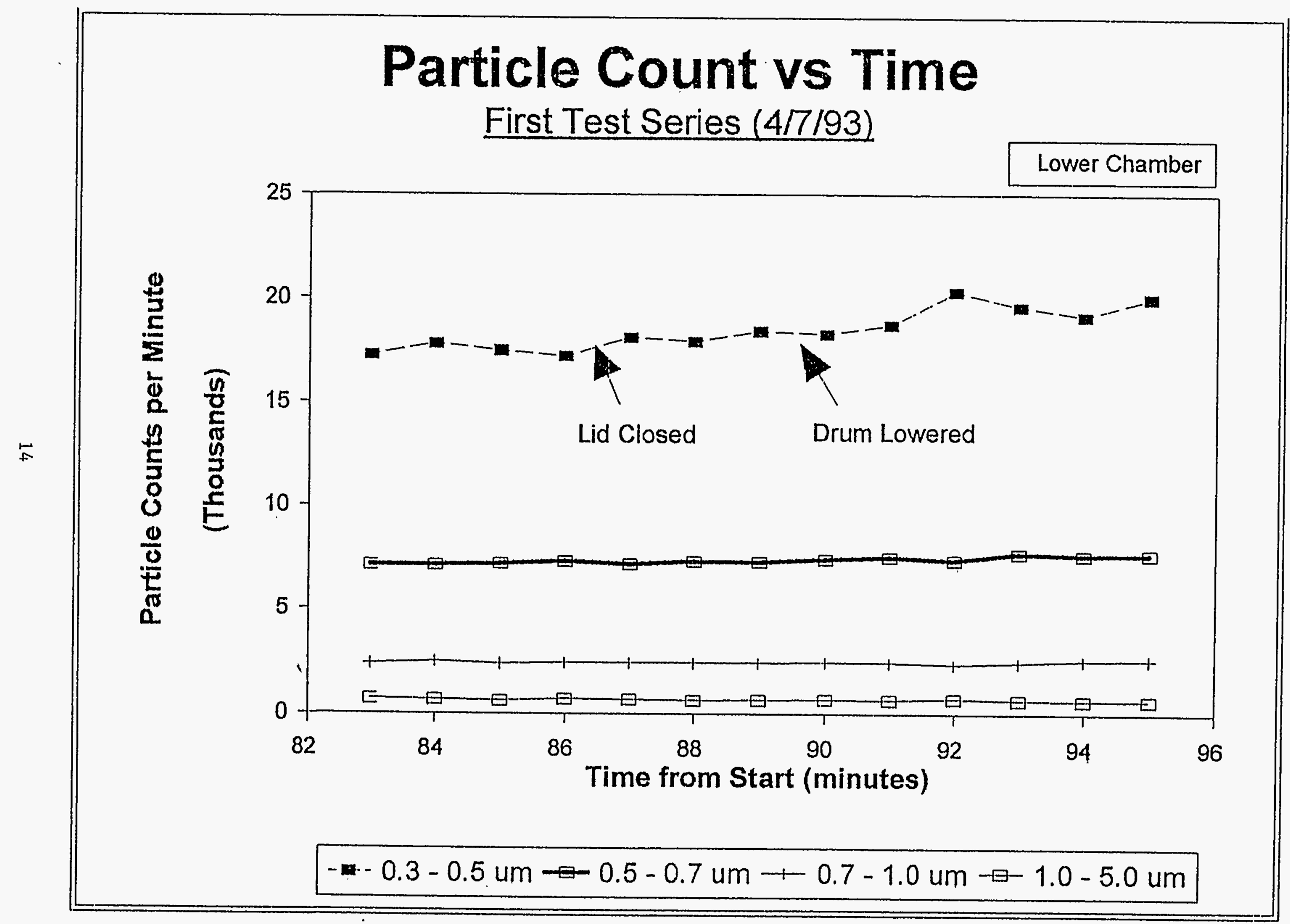

FIGUiRE 8. First Test Series, Final Door Closure. 


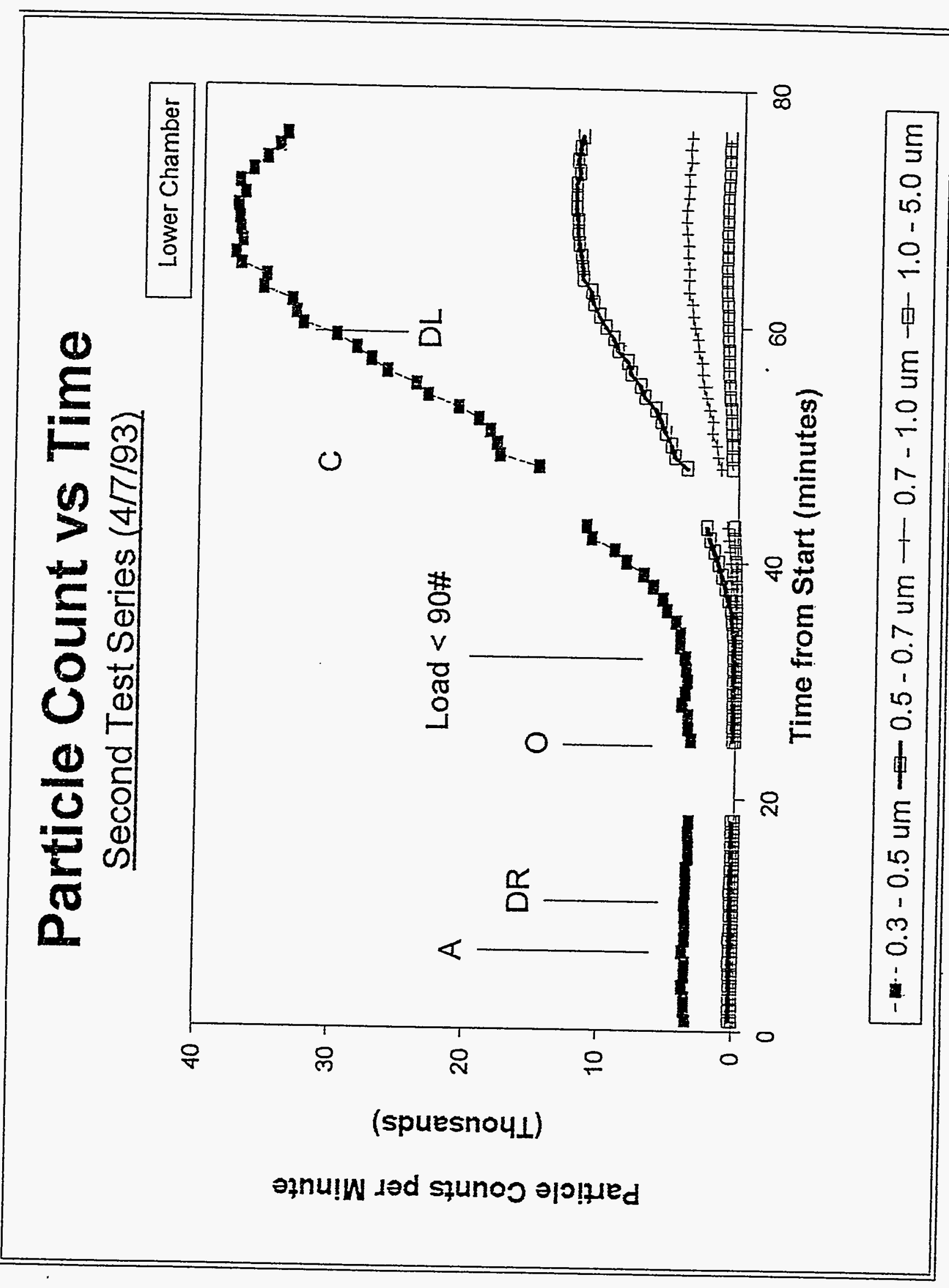




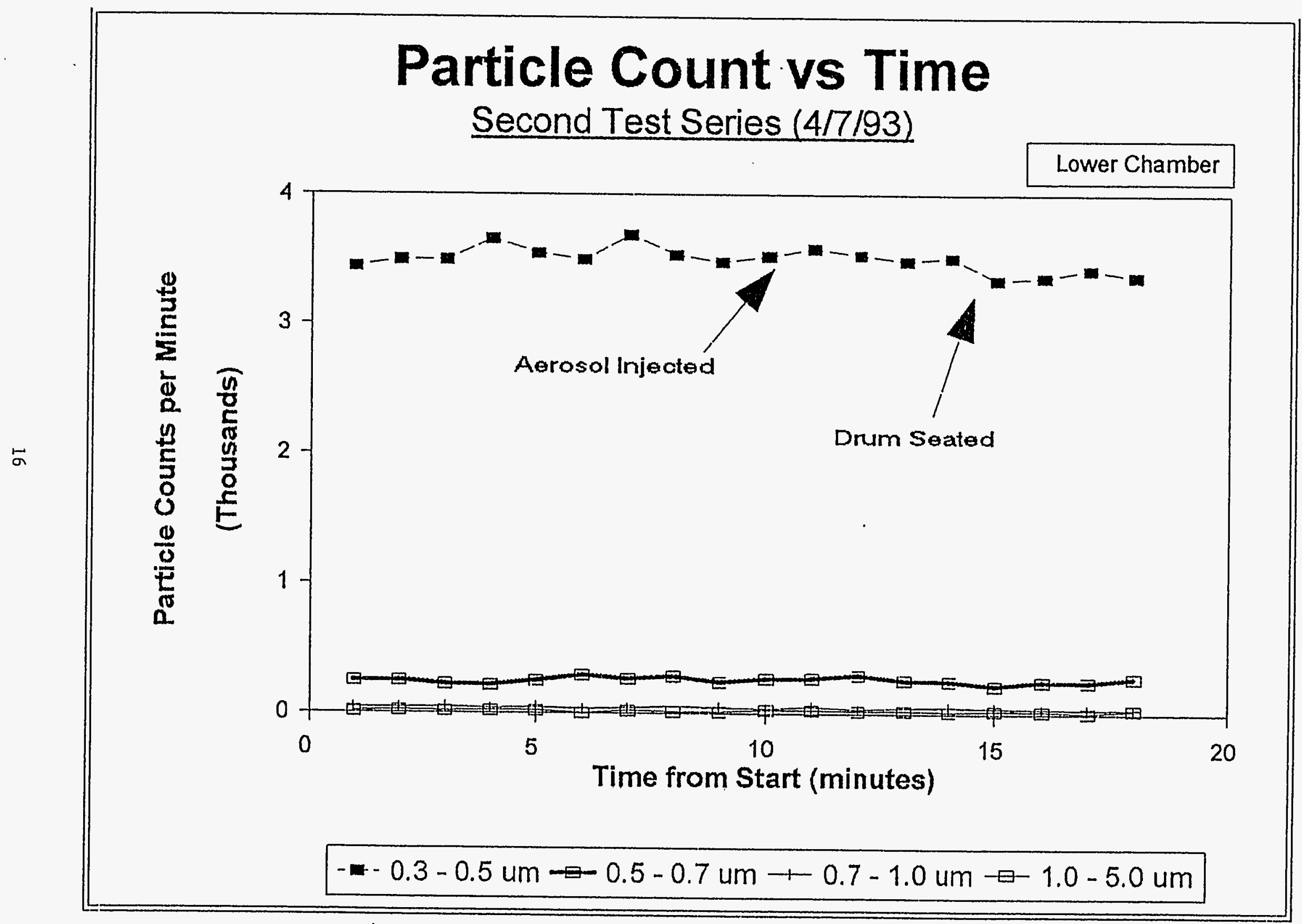

FIGURE 10. Second Test Series Prior to First Transfer Cycle. 


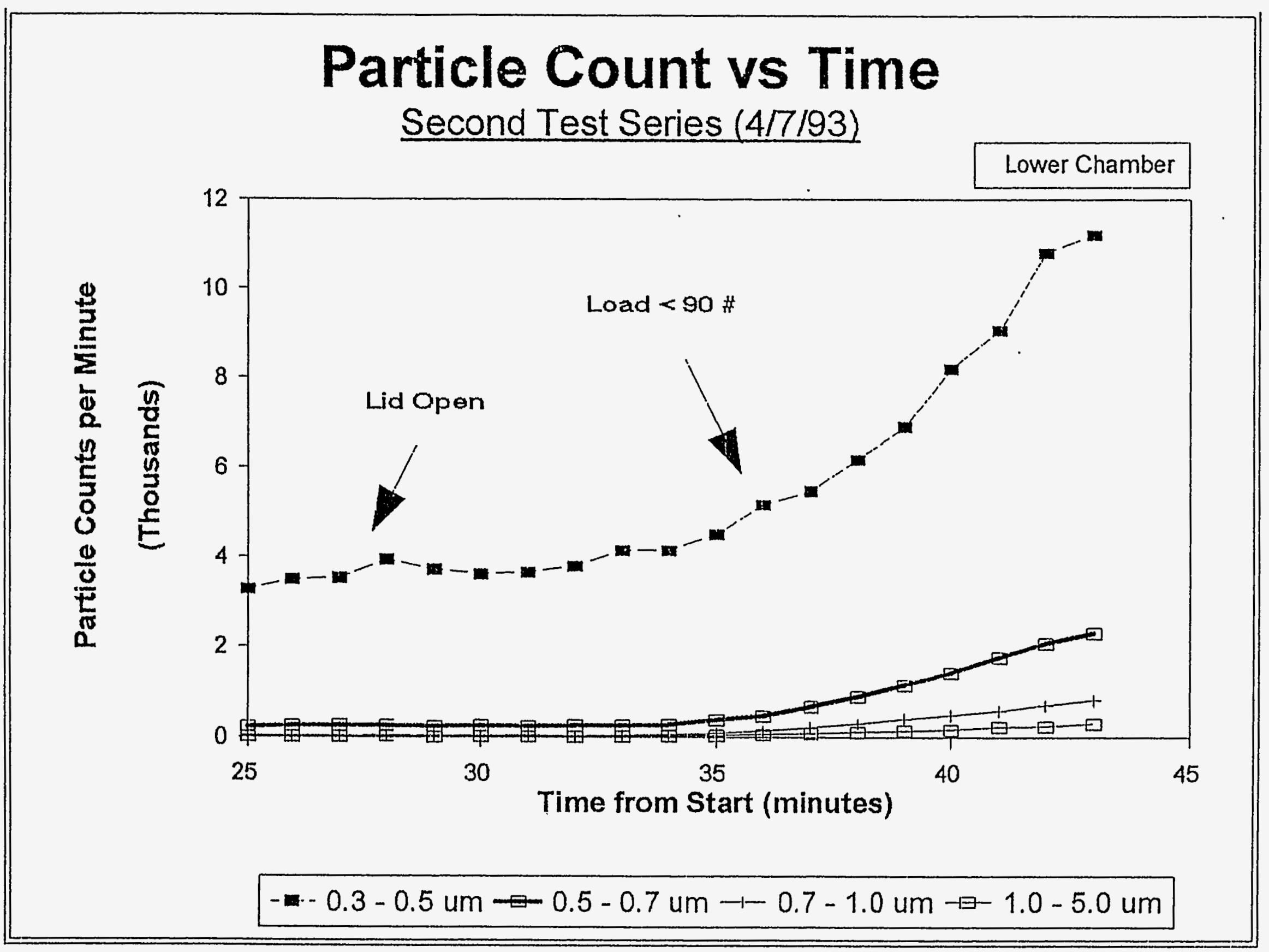

FIGURE 11. Second Test Series, Transfer Door Open; Pressure on Drum Seal Low at Point Noted. 


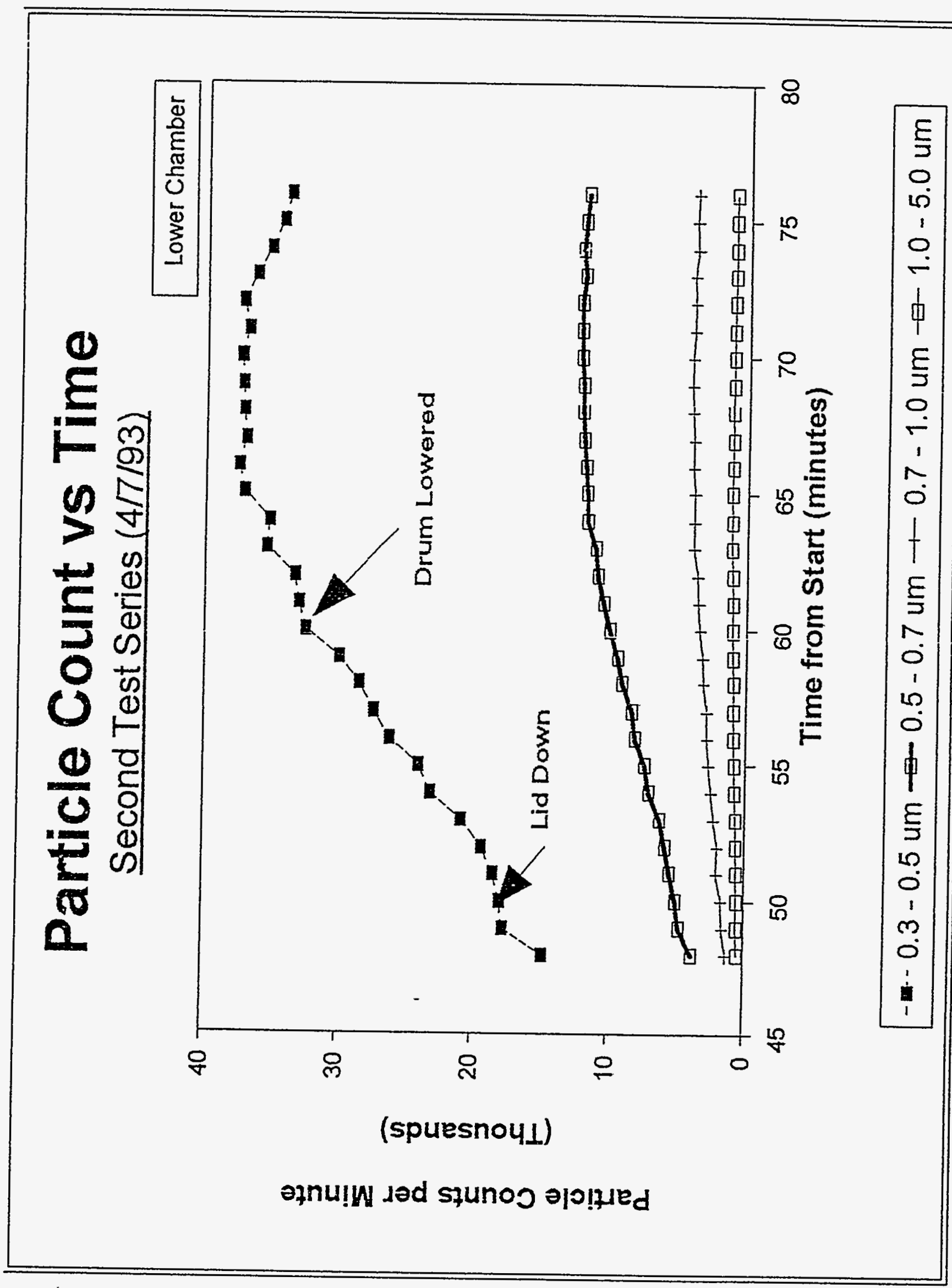




\subsection{Third Test Series}

Following the second test series, the drum seat (Hempelmann Boot) was examined for defects and conformance to the drum surface, and was heated to remove potentially outgassing materials that might influence the particle counts in the sealed test chambers. Following some smoothing of the joining surface between ends of the neoprene ring, the drum was again placed into the lower test chamber. The drum was raised against the sealing flange of the transfer door and clamped into position. By fixing the drum in the sealed position, the test could be performed with minimal changes in drum position and seating pressure on the neoprene gasket.

Figure 13 illustrates the resulting time-series plot for this third series. Comparing this series with the first two shows that the leak rate remains lower throughout the entire third series relative to either of the first two.

The data from the third test series do not result in a quantifiable leak rate. The detailed plots in Figures $i 4$ through 16 generally indicate some small increase in particle count following each door opening sequence but the count does not continue to increase beyond several counting intervals, suggesting that the increase was due either to resuspension of materials within the lower chamber, or to a momentary leak as the door opened and distorted the sealing surface (the motion of the mounting table is visibly evident as the door opened).

The one relatively large increase observed during this series occured following a changeover in particle counter attachment between the upper and lower chambers, and is likely attributable to minor air contamination carried over to the lower test chamber following that counting cycle in the upper chamber. The upper chamber was highly loaded with salt aerosol. 


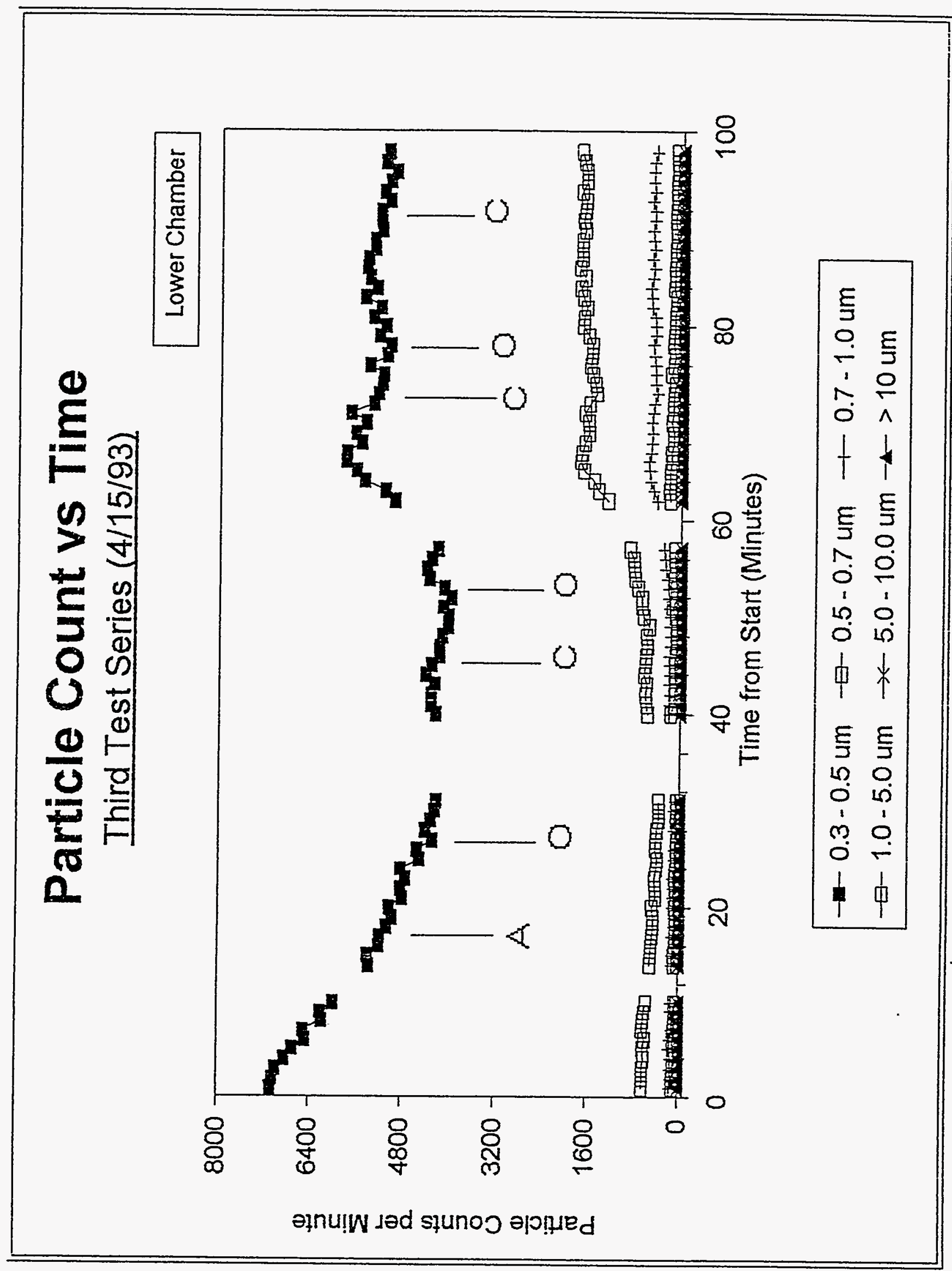




\section{Particle Count vs Time}

Third Test Series (4/15/93)

Lower Chamber

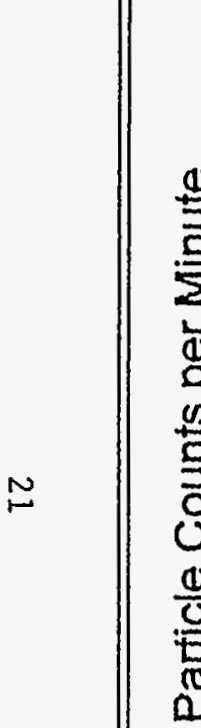

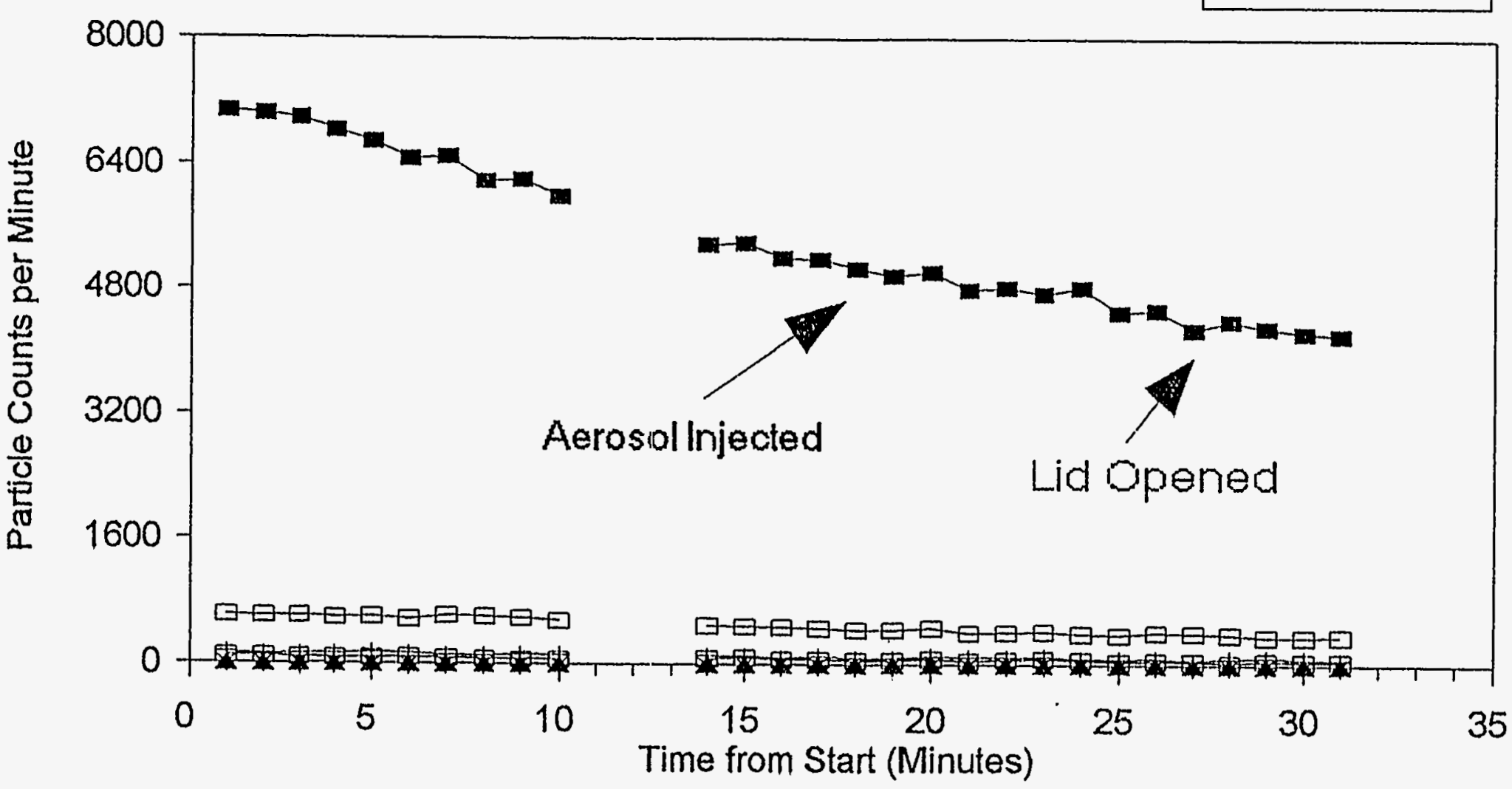

$$
\begin{aligned}
& -0.3-0.5 \mathrm{um} \rightarrow 0.5-0.7 \mathrm{um} \rightarrow 0.7-1.0 \mathrm{um} \\
& -\boxminus-1.0-5.0 \mathrm{um} \rightarrow-5.0-10.0 \mathrm{um} \rightarrow>10 \mathrm{um}
\end{aligned}
$$




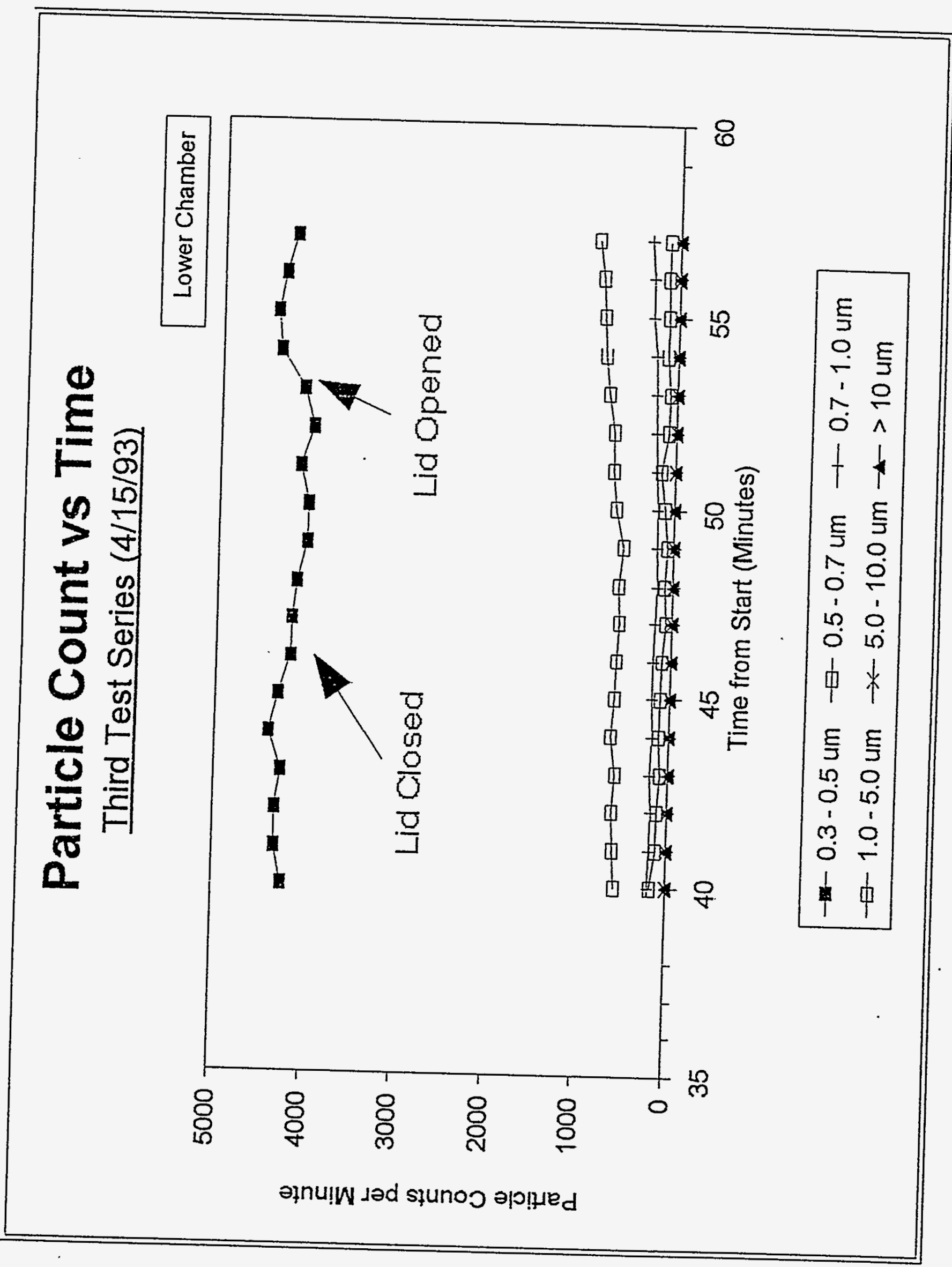




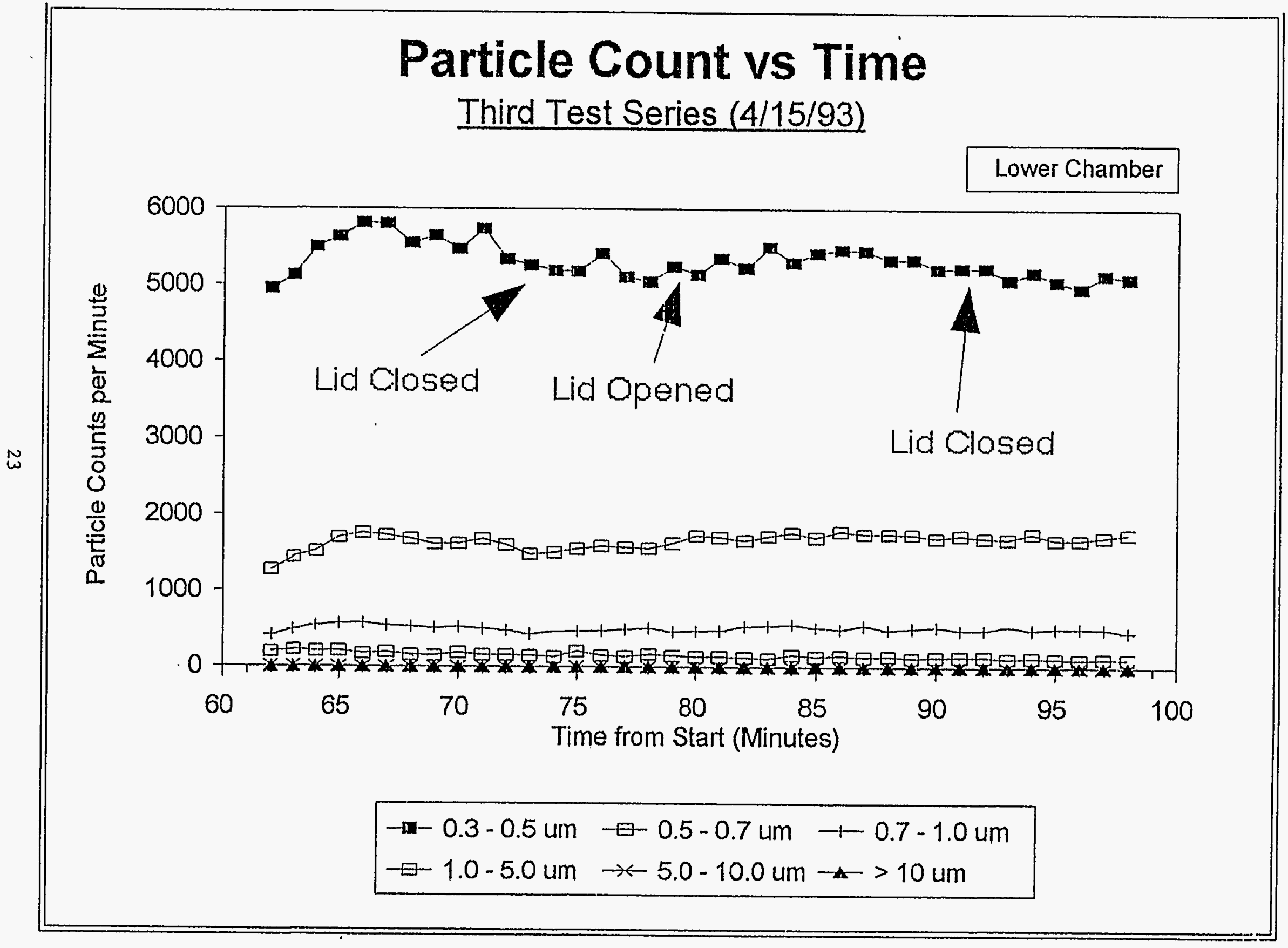

FIGURE 16. Final Cycle; Continuing to Demonstrate Good Population Stability. 


\section{Problems and other Observations}

Several problems were encountered while performing these leak tests. The most difficult to resolve were problems with the integrity of the seals in the glove ports and access door to the test chambers from the room. The next most troublesome was the necessity to continually "bump" the vertical lift in order to maintain a good seal between the drum and the transfer door's outer rim.

The lack of seal integrity around the door and around the glove ports resulted in a continuous influx of contaminated room air during the HEPA filtration cycles, and during the recirculation cycles that were needed to mix the aerosol and control differential pressure between the chambers. When the blowers were turned off immediately after a filtration cycle, particle counts increased three or four-fold while the test chambers equilibrated back to atmospheric pressure. In addition, since the recirculation blowers could not be operated without introducing room contamination, the mixing of the challenge aerosol was slow and appeared to be somewhat non-uniform. This resulted in increased uncertainty in the particle count rates and an unanticipated degradation in experimental sensitivity.

The need to continually increase the lift pressure was at best a nuisance during the tests, but also may have been a contributor to the observed leakage between the two chambers. If so, the exact mechanism is not obvious but could have been the result of the Hempelmann Boot deforming during the many readjustments of the sealing surface as the lift pressure changed. The third test series, with a fixed drum lift, showed no measurable leakage from this area.

Other points that caused some problems and would be best corrected before more tests are planned include the limitations imposed by having only a single HEPA filter that must be shared by the two test chambers, resulting in some potential for cross contamination, and the necessity to monitor both chambers with a single particle counter. The latter requirement appears to have also resulted in some cross contamination of the chambers during the third leak-test series. This source of leakage could not have been detected in the first two test series. 
These tests resulted in significant additional understanding of the problems that might be encountered while operating a bagless posting system. Modifications are required both to the method used to hold the shipping containers in place against the door lip during loading and to the design of the Hempelmann Boot to ensure a sealing surface that is less sensitive to position and contact pressure.

Tests were not performed with a differential pressure between the two chambers, as would be present in a standard working configuraton. Under the test conditions utilized, the leak potential of this system is measurable and could be potentially significant under worst-case conditions such as might occur if negative pressure could not be maintained in the upper, potentially contaminated chamber. The higest leak rate observed was 1.4 percent per minute.

A well-characterized estimate of "acceptable" leak rate is not possible with only the data available from this project. In order to estimate an acceptable rate, the amount of potential radiological challenge in the upper test chamber must be specified by the final user. It is possible, however, to generate a leak conversion factor that can be used to estimate the leakage of radiological material when the activity of the waste is known. For a particulate solid material or for liquids, 40 CFR 61 Appendix D, "Emission Factors", specifies an emission factor of 0.001 for suspension into the air. Given $1 \mathrm{nCi}$ of particulate matter in the drum to be transferred, $0.001 \mathrm{nCi}$ can be expected to become airborne during routine handling, in this conservative estimate. With a chamber leak rate of 1.4 percent per minute, $1.4 \mathrm{E}-5 \mathrm{nCi}$ would be expected to escape into the lower "reception" chamber during each minute of the transfer operation. The worst case leak conversion factor observed in these tests would be 1.4E-5 min-1. Should there be other sources of airborne contamination in the influent air, that contamination must also be taken into account in the estimate of total emissions. 


\section{Recommendations}

include:

These tests suggest several changes in the system prior to further testing. The changes

- Redesign the Hempelmann Boot to allow a better seal and one that is less sensitive to seating pressure and drum positioning.

- Modify the seating mechanism, possibly going from the lift table concept to one which directly clamps the drum lip into place against the transfer door's lip.

In addition to these system changes, other changes are recommended that would enhance the data collected in the future test series:

- $\quad$ Rework the chambers to obtain more reliable seals around the access door and the glove ports.

- $\quad$ Fit separate HEPA filtration units on the two test chambers, and fit valve assemblies that allow unambiguous switching between HEPA and recirculation modes of operation

- Plan on using two particle counters so that the potential for cross contamination between chambers is minimized, or at least change the plumbing to allow quick changes between chambers. The latter change will not minimize contamination transfer, but will eliminate potential particle contamination from the room air.

- Install a dryer in the aerosol generator assembly to minimize changes in particle size distribution during the experiments. 
Appendix A

TEST PLAN FOR

BAGLESS-POSTING SYSTEM

PARTICLE LEAK STUDY 
Test Plan

Leak Test of

Enclosed Leak Chamber

Double-Lid System

Bob Nininger

A test of the double-lid system, enclosed between two sealed leak chambers will characterize, quantitatively, the leak rate between the upper and lower chamber, and the sensitivity of that leak rate to particle size, Test conditions will be representative of static conditions with no drum in place, conditions with a drum in place but not open to the upper chamber, and conditions with a drum in place and opened to the upper chamber. Tests will be replicated sufficiently to obtain sufficient data to have 90 percent confidence in the analytical results for each configuration.

\section{Test equipment}

The test equipment will consist of a particle counter that can detect and count particles within six size ranges, specifically $0.3-0.5,0.5-1.0,1.0-5.0,5.0-10.0$ and $>10.0$ micrometer aerodynamic diameter, and an aerosol generator that can generate sufficient particles to provide a quantitative measure of leakage between the two chambers. A dilution system may need to be devised if the particle counts in the upper chamber are excessive.

\section{Leak Chamber Access}

The leak chamoers must each have two feed-through ports that allows sampling and return of the air inside the chambers. A quarter inch metal tube will be used to sample the aerosol.

The upper chamber must also provide a second feed-through port to provide input from the pressure regulated aerosol generator. Ideally, we must also exhaust an equivalent amount of air back to the pump, however the actual volume is very small, and we expect to not require exhaust air. (An alternative approach, if necessary, may be to provide power to the chamber and run the pump inside the chamber. This has the one drawback of not allowing easy access to the apparatus for adjustments although previous tests have shown the adjustments to require infrequent attention.)

\section{Test Approach}

The two test chambers, identified here as upper chamber and lower chamber, can be independently ventilated with recirculating blowers to reduce their pressure by as much a 4 inches of water. Connecting the two chambers is a pneumatically activated, rubber sealed hatch called a double-lid system. The test is designed to 
test this double-lid system. Tnis hatch is used to isolate the interior of a 55 gallon drum from its exterior, the inside being exposed to the environment of the upper test chamber and the outside, to the lower test chamber's environment. Leaks through this system connecting the two chambers must be characterized.

\section{Preparatory Tests}

Purge Test.-- Counts will be performed on the upper and lower chambers with only room aerosol present to determine the time required to purge that aerosol from the chambers using a HEPA filter attached in-line with the recirculating blowers.

Background Test -- The data from the purge test will also allow a quantification of the background aerosol we may have to tolerate during the quantitative measurements using a test aerosol. The test chambers may have to be scrubbed prior to testing if this background count proves to be too high.

Infiltration Test -- Counts will be performed on purged chambers with the HEPA filtration systems turned off, and with the recirculating blower running at a very low flow rate. The data from these tests will allow quantification of the infiltration rate of background and room aerosol which may interfere with the quantitative measurements.

Decay Test -- Counts will be performed on the upper chamber with the test aerosol inside and the aerosol generator turned off to determine the decay rate of the aerosol concentration. This operating mode will be necessary to perform the quantitative tests.

\section{Quantitative Tests}

Test Series 1 --

The test approach will be to pump the two chambers to slight negative pressures, with the top chamber being at the same pressure as the bottom one, or slightly more negative, with a HEPA filter attached to each recirculating blower. The HEPA filters will reduce the particle counts inside each chamber to levels that are similar to those inside a clean-room environment. (A preliminary test of the HEPA system will determine how long the purge will take and will characterize the background counts that we may have to live with.) After the chambers are sufficiently particle free, as measured by the particle counter coupled to each chamber individually, the aerosol generator will be turned on and the aerosol concentration allowed to reach an equilibrium within the upper chamber. During the equilibration the particle counter will alternately sample between the upper and lower chambers to measure any possible changes in lower chamber aerosol

concentration during the equilibration period. The aerosol

$$
A-2
$$


generator will be run at lowest possible flow rate to allow good mixing in the upper chamber during the equilibration.

After equilibration, the upper and lower chambers will be monitored for a period of time sufficient to quantify the variability of aerosol concentrations within the two chambers, and to quantify any possible leak that might be observed.

Should the infiltration rate of background or room aerosol be high enough to cause significant interference, or should the decay rate of the test aerosol be too high to run static tests with the blowers operating at their normal rates, the test protocol may require a reduced blower recirculation rate and/or slight positive pressure on the system.

Test Series 2 --

Following satisfactory completion of the first test series, a packing drum with lid and seal will be placed in the lower chamber, the arum will be opened to the upper atmosphere and the chambers purged of aerosol again using the recirculating HEPA filtration systems. The lid will be closed, the chambers purged for a short period of time, and the tests described in the first test series will be repeated.

Assuming the leak rate is still relatively low (yielding increases in count rate in the lower chamber that are less than or comparable to the variability in count ratel and the aerosol count in the lower chamber is sufficiently stable to represent a reproducible number, the double-lid system will be activated and the drum will be opened to the upper chamber while monitoring the particle counts in the lower chamber. A burst of particles will suggest that the seal is not intact; failure to see a burst of particles will suggest a good seal.

Assuming a satisfactory seal exists, counts will be performed alternately between the upper and lower chambers until equilibrium is again achieved in the upper chamber. (Equilibrium will be disturbed upon opening the drum because the air in the drum will not contain particles in the same concentration as in the upper chamber.) The leak rate will again be calculated from the count rates that are achieved under equilibrium conditions, with only natural wall-loss decay of the aerosol concentrations.

Test Series 3 --

Test Series 3 will follow immediately after Test series 2 . After Test 2 data are collected, the drum will be closed off from the upper chamber, and left in place against the double-lid seal. The two chambers will be alternately monitored and the resulting data will be used to estimate the leak rate, and measure the variability of the particle concentrations, just as in the first test. Should there be a leak between the drum interior and the 
lower chamber, that leak may show up as a gradually changing particle count in the lower chamber that is not correlated with any changes in particle concentration in the upper chamber.

Test Series 4 --

Following the same setup as preceded Test series 3 , the drum will be closed from the upper chamber and lowered from its sealed position while monitoring the lower chamber.

The two chambers will continue to be alternately monitored as in Test 3. This test will determine whether the lidded drum has much potential for emitting particles prior to capping and ringing around the lip. An interfering source of particles could be the double-lid system's seal to the upper chamber. In either case, the data will show the amount of leakage that might occur during this removal process.

Tests that might follow --

Eollowing satisfactory completion of the first test series, we probably should anticipate some changes in the test procedures or adjustments to the double-lid apparatus. A second series of tests, similar or even identical to the first would then be performed to characterize the system with the changes.

Another consideration might be to characterize the behavior of the double-lid isolation system with a number of different drums and/or a variety of different seal conditions (lift pressure or drum conformity, for examples) If the test protocol is satisfactory, a series of such tests could be run.

Analysis of the Data

Displavs

The data can be displayed in several formats:

Time-series of upper-chamber and lower-chamber particle counts, both on the same graph (use logarithmic scale if necessary)

Time-series of the ratio of lower:upper particle counts after equilibrium is established.

Time-series of ratio of lower:upper particle counts as particles build up in the lower chamber.

- Time-series of Leak Rate Coefficient 


\section{Analytical Algorithms}

The data analysis will require a set of relatively simple algorithms, each to be applied to averaged counts for each size range, and to the total averaged counts over all size ranges. The simplest leak algorithm will be:

Leak Fraction = Lower Chamber Count/Upper Chamber Count

Assuming the recirculation filtration is stopped prior to each test, a leak rate coefficient can be calculated:

- Leak Rate coefficient = Change in Lower Chamber Count/

(Time X Average Upper Chamber count)

other information that must be derived from the data relate to variability in the count rates, to establish the precision of the results. These include variability in equilibrium counts, both upper and lower chambers (the lower, only if equilibrium is established), and variability in leak rate and leak rate coefficient, as appropriate. The variability will be characterized by the standard deviation of repeated measurements and simple propagation of error calculations. 


\section{Test Flow Charts}

Purge/Background/Infiltration Test

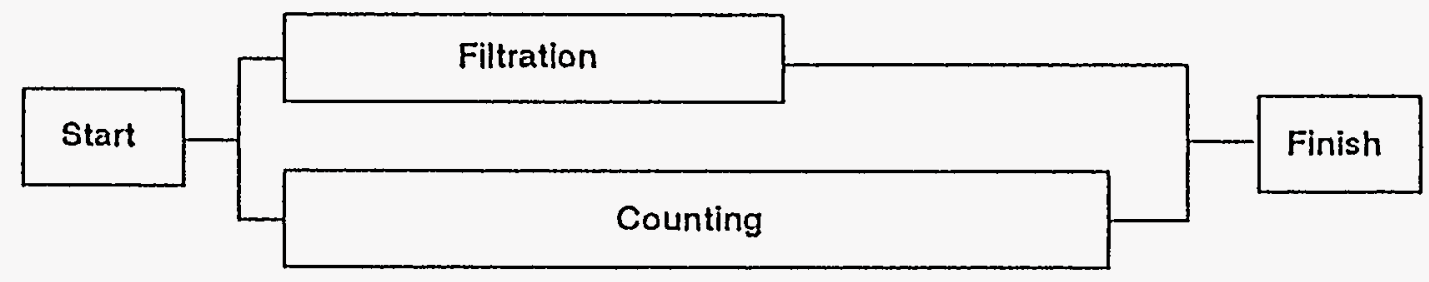

Particle Decay Test

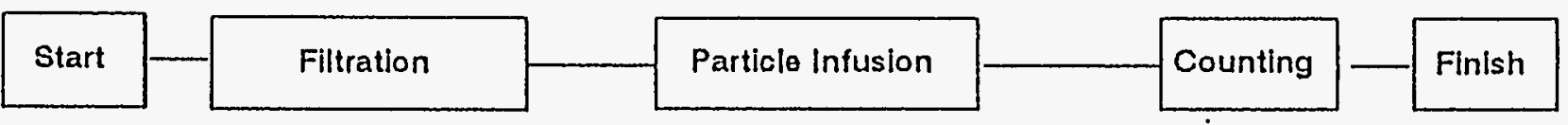

Cyclic Test Between Chambers

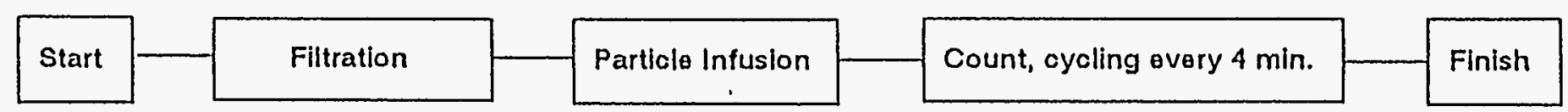

Drum Cycle Test

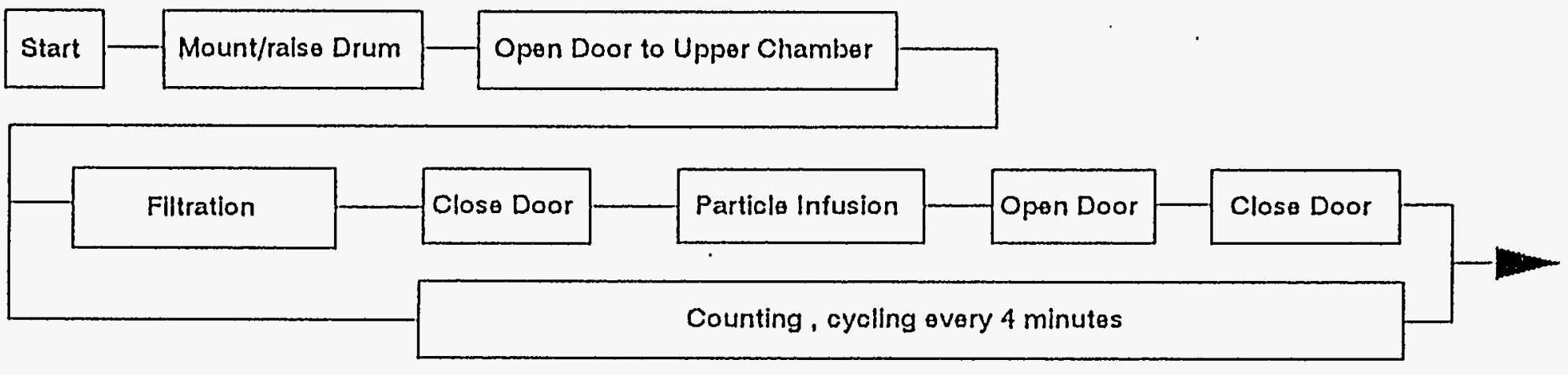


Double Seal Test

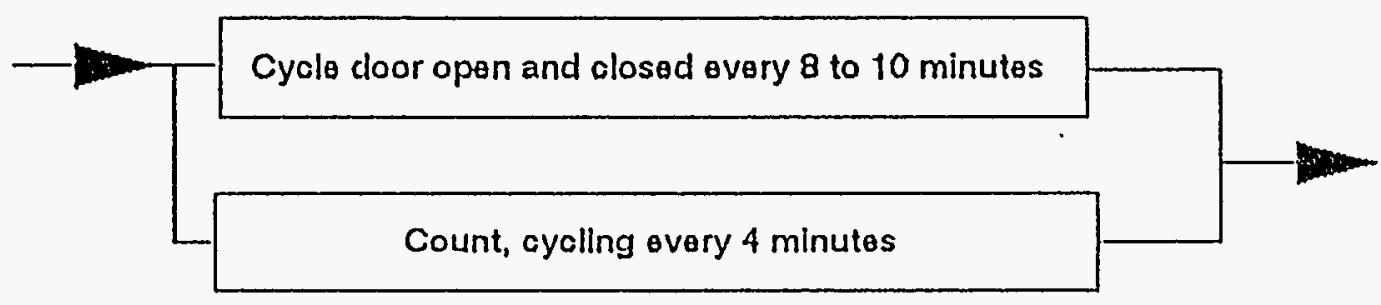

\section{Passive Drum Test}

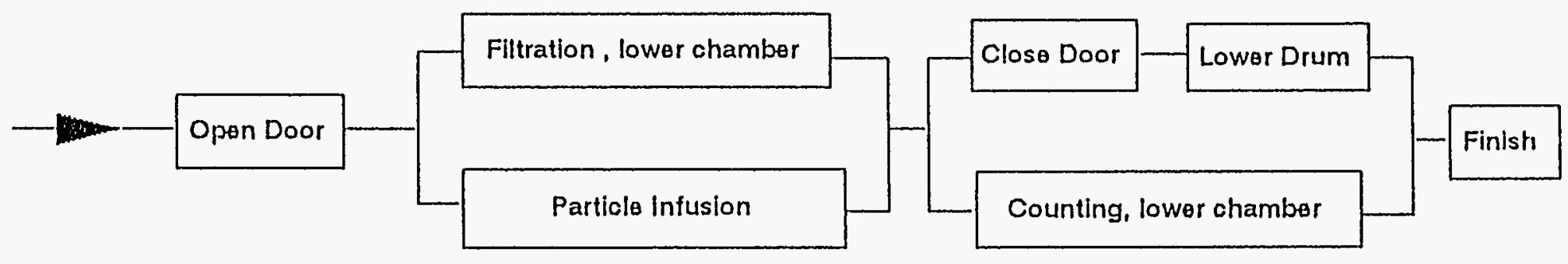


PREPARATORY TEST SERIES Date:

\begin{tabular}{|c|l|l|}
\hline STEP & SAMPLER SETTINGS $=$ & $\begin{array}{l}\text { Sample Duration }= \\
\text { Sample Interval }=\end{array}$ \\
\hline 1 & $\begin{array}{l}\text { HEPA off (BACKGROUND) } \\
\text { number of cycles }=\end{array}$ & Upper chamber Lower chamber \\
\hline 3 & $\begin{array}{l}\text { HEPA on (PURGE) } \\
\text { number of cycles }= \\
\text { (DECAY off/Generator on/Door closed } \\
\text { number of cycles }= \\
\text { HEPA off/Generator off } \\
\text { number of cycles }=\end{array}$ & $\begin{array}{l}\text { Time On }= \\
\text { Upper Chamber } \quad \text { Lower Chamber } \\
\text { Upper Chamber Lower Chamber }\end{array}$ \\
\hline
\end{tabular}


CHAMBER TEST SERIES 1

Date:

\begin{tabular}{|c|c|c|c|}
\hline STEP & SAMPLER SETTINGS = & $\begin{array}{l}\text { Sample Duration : } \\
\text { Sample Interval = }\end{array}$ & \\
\hline 1 & $\begin{array}{l}\text { HEPA on (PURGE) } \\
\text { number of cycles = NOTE: alternate }\end{array}$ & $\begin{array}{l}\text { Time On = } \\
\text { Upper Chamber }\end{array}$ & Lower Chamber \\
\hline 3 & $\begin{array}{l}\text { HEPA off/Generator on/Door closed } \\
\text { (CYCLIC TEST BETWEEN CHAMBERS } \\
\text { number of cycles = } \\
\text { HEPA off/Generator off } \\
\text { number of cycles = NOTE: alternate }\end{array}$ & $\begin{array}{l}\text { Time On = } \\
\text { Upper Chamber } \\
\text { Time Off = } \\
\text { Upper Chamber }\end{array}$ & $\begin{array}{l}\text { Lower Chamber } \\
\text { Lower Chamber }\end{array}$ \\
\hline
\end{tabular}


DRUM TEST SERIES 2, 3 AND 4 Date:

\begin{tabular}{|c|c|c|c|}
\hline STEP & SAMPLER SETTINGS = & $\begin{array}{l}\text { Sample Duration } \\
\text { Sample Interval = }\end{array}$ & \\
\hline 1 & $\begin{array}{l}\text { HEPA on/Drum in place/lid open } \\
\text { (PURGE) } \\
\text { number of cycles = NOTE: alternate }\end{array}$ & $\begin{array}{l}\text { Time On }= \\
\text { Upper Chamber }\end{array}$ & Lower Chamber \\
\hline 2 & $\begin{array}{l}\text { HEPA on/Drum in place/lid closed } \\
\text { (PURGE) } \\
\text { number of cycles = NOTE!! }\end{array}$ & $\begin{array}{l}\text { Time On = } \\
\text { Upper Chamber } \\
\text { one cycle }\end{array}$ & $\begin{array}{l}\text { Lower Chamber } \\
\text { one cycle }\end{array}$ \\
\hline 3 & $\begin{array}{l}\text { HEPA off/Generator on/Door closed } \\
\text { (DRUM CYCLE TEST) } \\
\text { number of cycles = }\end{array}$ & $\begin{array}{l}\text { Time On }= \\
\text { Upper Chamber }\end{array}$ & Lower Chamber \\
\hline 4 & $\begin{array}{l}\text { HEPA off/Generator off/Door open } \\
\text { number of cycles = NOTE: lower first }\end{array}$ & $\begin{array}{l}\text { Time Open = } \\
\text { Upper Chamber }\end{array}$ & Lower Chamber \\
\hline 5 & $\begin{array}{l}\text { HEPA off/Generator off/Door closed } \\
\text { number of cycles = NOTE: alternate }\end{array}$ & $\begin{array}{l}\text { Time Closed = } \\
\text { Upper Chamber }\end{array}$ & Lower Chamber \\
\hline 6 & $\begin{array}{l}\text { HEPA off/Generator off/Door open } \\
\text { (LABELED SERIES } 3 \text { IN TEXT) } \\
\text { number of cycles = NOTE: lower ONLY!! }\end{array}$ & $\begin{array}{l}\text { Time Open }= \\
\text { Upper Chamber } \\
\quad x \times x \times x \times x\end{array}$ & Lower Chamber \\
\hline 7 & $\begin{array}{l}\text { HEPA off/Generator off/Door closed } \\
\text { number of cycles = NOTE: lower ONLY!! }\end{array}$ & $\begin{array}{l}\text { Time Closed }= \\
\text { Upper Chamber } \\
\quad X X X X X X X\end{array}$ & Lower Chamber \\
\hline 8 & $\begin{array}{l}\text { HEPA off/Generator off/Door Closed/ } \\
\text { Drum down (LABELED SERIES } 4 \text { IN TEX } \\
\text { number of cycles = NOTE: lower ONLY!! }\end{array}$ & $\begin{array}{l}\text { Time Open }= \\
\text { Upper Chamber } \\
\quad x \times x \times x \times x\end{array}$ & Lower Chamber \\
\hline 9 & $\begin{array}{l}\text { HEPA off/Generator off/Door closed } \\
\text { number of cycles = NOTE: lower ONLY!! }\end{array}$ & $\begin{array}{l}\text { Time Closed }= \\
\text { Upper Chamber } \\
\quad x \times \times \times \times \times x\end{array}$ & Lower Chamber \\
\hline
\end{tabular}


Appendix B

\section{PARTICLE COUNTING DATA}

Chamber Set-up Testing

4/7/93 -- First Test Series

4/7/93 -- Second Test Series

4/11/92 -- Third Test Series 
PRELIMINARY DATA. TESTING SETUP CONDITIONS (4/6/93)

\begin{tabular}{|c|c|c|}
\hline \multicolumn{3}{|c|}{$0.3-0.5 \mathrm{um}$} \\
\hline TIME & Lower Chamber & Upper Chamber \\
\hline 0 & 9634 & \\
\hline 70 & 9428 & \\
\hline 140 & 9264 & \\
\hline 210 & 9418 & \\
\hline 280 & 8969 & \\
\hline 350 & 9030 & \\
\hline 420 & 8862 & \\
\hline 490 & 8750 & \\
\hline 560 & 8680 & \\
\hline 929 & & 205858 \\
\hline 999 & & 281194 \\
\hline 1069 & & 161872 \\
\hline 1139 & & 93753 \\
\hline 1277 & 8479 & \\
\hline 1347 & 8665 & \\
\hline 1417 & 8841 & \\
\hline 1487 & 8615 & \\
\hline 1557 & 8437 & \\
\hline 1627 & 8511 & \\
\hline 1732 & & 188864 \\
\hline 1802 & & 189152 \\
\hline 1872 & & 191452 \\
\hline 1942 & & 196439 \\
\hline 2012 & & 199111 \\
\hline 2129 & 8283 & \\
\hline 2199 & 8187 & \\
\hline 2269 & 8155 & \\
\hline 2339 & 8125 & \\
\hline 2409 & 7897 & \\
\hline 2518 & & 213418 \\
\hline 2588 & & 213421 \\
\hline 2658 & & 217381 \\
\hline 2728 & & 222372 \\
\hline 2798 & & 227603 \\
\hline 2926 & 7952 & \\
\hline 2996 & 7810 & \\
\hline 3066 & 7743 & \\
\hline 3136 & 7702 & \\
\hline 3206 & 7704 & \\
\hline
\end{tabular}

B-1 
FIRST TEST SERIES

\begin{tabular}{|c|c|c|c|c|c|c|c|c|c|c|c|c|c|}
\hline \multirow{3}{*}{$\begin{array}{l}\text { Notes: } \\
\text { Stable Lower Chamber }\end{array}$} & \multirow{2}{*}{$\begin{array}{l}\text { Time of Sanple } \\
\text { min.from start }\end{array}$} & \multicolumn{4}{|c|}{ Count per Cliannel } & \multicolumn{2}{|c|}{ Sampl.T/m.0 = of soc } & \multicolumn{6}{|c|}{ Upper Chamber } \\
\hline & & $0.3-0.5$ & 0.5 .0 .7 & $0.7-1.0$ & $1.0-5.0$ & $5.0-10.0$ & $>10.0$ & $0.3-0.5$ & 0.5 .0 .7 & $0.7-1.0$ & $1.0-5.0$ & $5.0-10.0$ & $>10.0$ \\
\hline & 1 & 2969 & 221 & 48 & 27 & 1 & 0 & & & & & & \\
\hline & 2 & 3012 & 205 & 59 & 34 & 0 & 0 & & & & & & \\
\hline & 3 & 3095 & 235 & 53 & 36 & 0 & 0 & & & & & & \\
\hline & 4 & 2984 & 242 & 67 & 38 & 1 & 0 & & & & & & \\
\hline & 5 & 309.4 & 252 & 47 & 41 & 1 & 0 & & & & & & \\
\hline & 0 & 3046 & 232 & 55 & 37 & 1 & 1 & & & & & & \\
\hline & 7 & 3008 & 223 & 53 & 19 & 0 & 0 & & & & & & \\
\hline & 8 & 2943 & 202 & 42 & 26 & 1 & 0 & & & & & & \\
\hline & 9 & 3053 & 195 & 37 & 29 & 1 & 0 & & & & & & \\
\hline & 10 & 2899 & 237 & 49 & 28 & 3 & 0 & & & & & & \\
\hline & 11 & 2945 & 235 & 58 & 54 & 3 & 2 & & & & & & \\
\hline & 12 & 2965 & 204 & 53 & 32 & 1 & 0 & & & & & & \\
\hline & 13 & 2859 & 229 & 59 & 35 & 1 & 0 & & & & & & \\
\hline & 14 & 2802 & 218 & 60 & 17 & 0 & 0 & & & & & & \\
\hline & 15 & 2790 & 218 & 31 & 31 & 1 & 1 & & & & & & \\
\hline & 16 & 2745 & 205 & 37 & 21 & 0 & 0 & & & & & & \\
\hline & 17 & 2687 & 192 & 34 & 28 & 0 & 0 & & & & & & \\
\hline & 18 & 2642 & 196 & 44 & 31 & 1 & 0 & & & & & & \\
\hline & 19 & 2671 & 205 & 43 & 32 & 1 & 0 & & & & & & \\
\hline & 20 & 2592 & 226 & 39 & 19 & 1 & 0 & & & & & & \\
\hline Aerosol Injected (upper) & 21 & 2614 & 192 & 42 & 33 & 2 & 0 & & & & & & \\
\hline & 22 & 2495 & 183 & 39 & 42 & 0 & 0 & & & & & & \\
\hline & 23 & 2507 & 193 & 41 & 26 & 0 & 0 & & & & & & \\
\hline & 24 & 2503 & 158 & 28 & 23 & 0 & 0 & & & & & & \\
\hline & 25 & 2381 & 174 & 31 & 15 & 1 & 0 & & & & & & \\
\hline & 26 & 2250 & 182 & 36 & 19 & 0 & 0 & & & & & & \\
\hline & $\begin{array}{l}27 \\
28\end{array}$ & & & & & & & & & & & & \\
\hline & $\begin{array}{l}28 \\
29\end{array}$ & & & & & & & 81302 & $\begin{array}{l}226732 \\
240 ? 60\end{array}$ & $\begin{array}{l}264077 \\
365991\end{array}$ & $\begin{array}{l}335694 \\
304815\end{array}$ & $\begin{array}{l}9.45 \\
56 ?\end{array}$ & $\begin{array}{l}3 \\
2\end{array}$ \\
\hline & 30 & & & & & & & 92030 & $240<100$ & 205991 & 304010 & 002 & 2 \\
\hline & 31 & 2215 & 163 & 43 & 23 & 0 & 0 & & & & & & \\
\hline & 32 & 22013 & 172 & 37 & 14 & 1 & 0 & & & & & & \\
\hline & 33 & 2170 & 15.4 & 23 & 28 & 0 & 0 & & & & & & \\
\hline
\end{tabular}


FIRST TEST SERIES

\begin{tabular}{|c|c|c|c|c|c|c|c|c|c|c|c|c|c|}
\hline \multirow[t]{5}{*}{ Drurn Raised to Position } & 34 & 2158 & 168 & 35 & 38 & 1 & $1 \|$ & & & & & & \\
\hline & 35 & 2100 & 191 & 44 & 33 & 1 & 0 & & & & & & \\
\hline & 36 & 2015 & 174 & 30 & 29 & 0 & 2 & & & & & & \\
\hline & 37 & 2020 & 213 & 32 & 26 & 0 & 0 & & & & & & \\
\hline & 38 & 2015 & 180 & 38 & 32 & 0 & 0 & & & & & & \\
\hline \multirow{5}{*}{ Lid Open } & 39 & 1991 & 183 & 45 & 27 & 0 & 0 & & & & & & \\
\hline & 40 & 2012 & 203 & 44 & 26 & 0 & 0 & & & & & & \\
\hline & 41 & 2057 & 228 & 75 & 46 & 0 & 0 & & & & & & \\
\hline & 42 & 2231 & 254 & 55 & 42 & 0 & 0 & & & & & & \\
\hline & 43 & 2425 & 337 & 113 & 54 & 0 & 0 & & & & & & \\
\hline \multirow[t]{15}{*}{1} & 44 & 2645 & 457 & 156 & 79 & 0 & 0 & & & & & & \\
\hline & 45 & 2982 & 676 & 222 & 75 & 0 & 0 & & & & & & \\
\hline & 46 & 3603 & 832 & 291 & 105 & 0 & 0 & & & & & & \\
\hline & 47 & 4175 & 1048 & 345 & 120 & 0 & 0 & & & & & & \\
\hline & 48 & & & & & & & & & & & & \\
\hline & 49 & & & & & & & 74541 & 253372 & 334099 & 300784 & 148 & 0 \\
\hline & 50 & & & & & & & 78221 & 258618 & 332892 & 290044 & 101 & 0 \\
\hline & 51 & & & & & & & 84316 & 268893 & 330616 & 273993 & 134 & 0 \\
\hline & 52 & & & & & & & & & & & & \\
\hline & 53 & 8330 & 2602 & 875 & 280 & 0 & 0 & & & & & & \\
\hline & 54 & 8345 & 2907 & 1009 & 323 & 2 & 0 & & & & & & \\
\hline & 55 & 9814 & 3109 & 1020 & 351 & 1 & 0 & & & & & & \\
\hline & 56 & 10013 & 3232 & 116.4 & 383 & 0 & 0 & & & & & & \\
\hline & 57 & 10801 & 3513 & 1239 & 413 & 0 & 0 & & & & & & \\
\hline & 58 & 11674 & 3903 & 1312 & 431 & 3 & 0 & & & & & & \\
\hline Lid Closing & 59 & 11808 & 4124 & 1415 & 405 & 0 & 0 & & & & & & \\
\hline \multirow[t]{4}{*}{ Lid Closed } & 60 & 13447 & 4417 & 1523 & 460 & 1 & 0 & & & & & & \\
\hline & 61 & 12341 & 4628 & 1645 & 487 & 0 & 0 & & & & & & \\
\hline & 62 & 15072 & 4782 & 1736 & 538 & 0 & 0 & & & & & & \\
\hline & 63 & 17203 & 5294 & 1794 & 532 & 0 & 0 & & & & & & \\
\hline \multirow[t]{5}{*}{ Drum Lowered } & 64 & 17390 & 5685 & 1862 & 555 & 0 & 0 & & & & & & \\
\hline & 65 & 16893 & 5816 & 1999 & 561 & 0 & 2 & & & & & & \\
\hline & 66 & 17824 & 5858 & 2019 & 582 & 0 & 0 & & & & & & \\
\hline & 67 & 17881 & 6175 & 2018 & 579 & 1 & 0 & & & & & & \\
\hline & 68 & 17458 & 6516 & 2281 & 635 & 0 & 0 & & & & & & \\
\hline
\end{tabular}


FIRST TEST SERIES

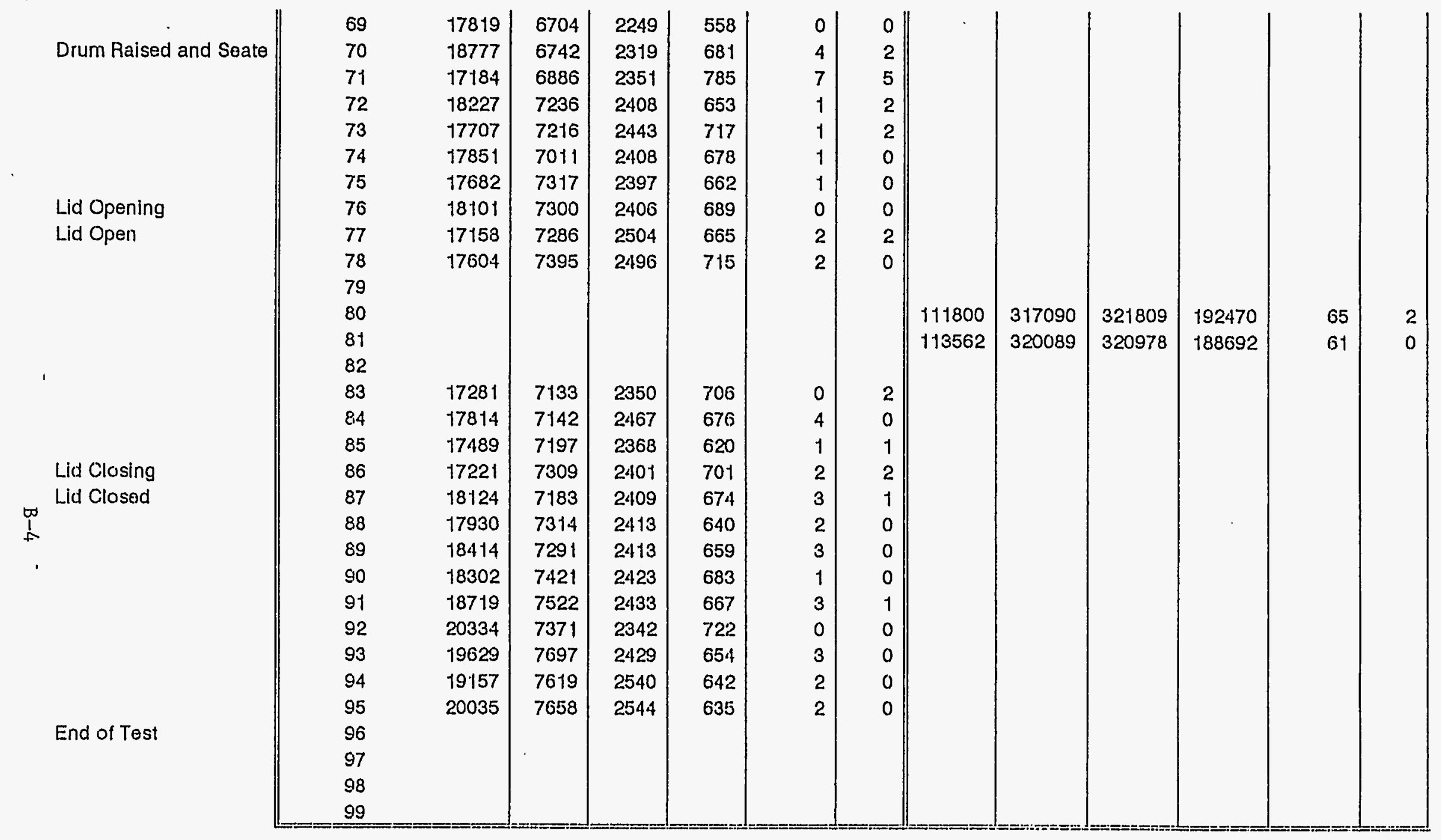


SECOND TEST SERIES

Notes:

\begin{tabular}{|c|c|c|c|c|c|c|c|c|c|c|c|c|}
\hline \multirow{2}{*}{$\begin{array}{l}\text { Time of Sample } \\
\text { min.from start }\end{array}$} & \multicolumn{4}{|c|}{ Count per Channel } & \multicolumn{2}{|c|}{ Sampl.TImo $=81900$} & \multicolumn{6}{|c|}{ Upper Chamber } \\
\hline & $0.3 \cdot 0.5$ & 0.5 .0 .7 & $0.7-1.0$ & $1.0-5.0$ & $5.0-10.0$ & $>10.0$ & $0.3-0.5$ & 0.5 .0 .7 & $0.7-1.0$ & $1.0-5.0$ & $5.0-10.0$ & $\geq 10.0$ \\
\hline 1 & 3442 & 249 & 45 & 17 & 0 & 0 & & & & & & \\
\hline 2 & 3493 & 252 & 42 & 22 & 1 & 0 & & & & & & \\
\hline 3 & 3495 & 223 & 49 & 19 & 1 & 0 & & & & & & \\
\hline 4 & 3657 & 218 & 41 & 24 & 0 & 0 & & & & & & \\
\hline 5 & 3547 & 251 & 48 & 22 & 0 & 0 & & & & & & \\
\hline 6 & 3497 & 293 & 37 & 6 & 0 & 0 & & & & & & \\
\hline 7 & 3687 & 265 & 45 & 22 & 0 & 1 & & & & & & \\
\hline 8 & 3534 & 287 & 59 & 17 & 0 & 0 & & & & & & \\
\hline 9 & 3481 & 241 & 48 & 14 & 0 & 0 & & & & & & \\
\hline 10 & 3526 & 270 & 41 & 30 & 1 & 0 & & & & & & \\
\hline 11 & 3584 & 273 & 53 & 29 & 2 & 0 & & & & & & \\
\hline 12 & 3536 & 299 & 38 & 24 & 0 & 0 & & & & & & \\
\hline 13 & 3492 & 260 & 49 & 27 & 1 & 0 & & & & & & \\
\hline 14 & 3515 & 252 & 54 & 19 & 0 & 0 & & & & & & \\
\hline 15 & 3343 & 213 & $4 B$ & 25 & 0 & 0 & & & & & & \\
\hline 16 & 3365 & 250 & 39 & 24 & 0 & 0 & & & & & & \\
\hline 17 & 3423 & 244 & 36 & 12 & 0 & 0 & & & & & & \\
\hline 18 & 3373 & 276 & 40 & 33 & 0 & 1 & & & & & & \\
\hline 19 & & & & & & & & & & & & \\
\hline 20 & & & & & & & 58184 & 211782 & 316671 & 378755 & 365 & 0 \\
\hline 21 & & & & & & & 61682 & 216900 & 310767 & 368811 & 373 & 0 \\
\hline 22 & & & & & & & 61831 & 208064 & 291246 & 387786 & 557 & $t$ \\
\hline 23 & & & & & & & 67366 & 224677 & 307758 & 353710 & 348 & 0 \\
\hline 24 & & & & & & & & & & & & \\
\hline 25 & 3286 & 233 & 50 & 30 & 1 & 0 & & & & & & \\
\hline 26 & 3505 & 261 & 47 & 22 & 1 & 0 & & & & & & \\
\hline 27 & 3537 & 273 & 46 & 27 & 2 & 0 & & & & & & \\
\hline 28 & 3939 & 261 & 55 & 42 & 0 & 0 & & & & & & \\
\hline 29 & 3722 & 250 & 42 & 20 & 1 & 0 & & & & & & \\
\hline 30 & 3614 & 264 & 46 & 22 & 1 & 0 & & & & & & \\
\hline 31 & 3661 & 245 & 53 & 28 & 1 & 0 & & & & & & \\
\hline 32 & 3783 & 267 & 39 & 18 & 0 & 0 & & & & & & \\
\hline 33 & 4151 & 269 & 54 & 30 & 0 & 0 & & & & & & \\
\hline
\end{tabular}




\begin{tabular}{|c|c|c|}
\hline & 00 & \\
\hline & $\stackrel{\omega}{\sim} \underset{\infty}{\sigma}$ & \\
\hline & 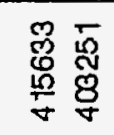 & \\
\hline & 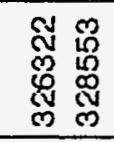 & \\
\hline & 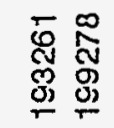 & \\
\hline & 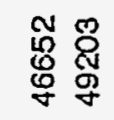 & \\
\hline 000000000 & & 000000000000000000000 \\
\hline ToONOOTror & & 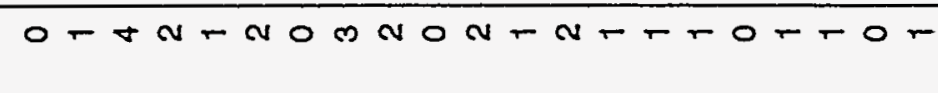 \\
\hline 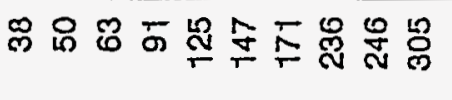 & & 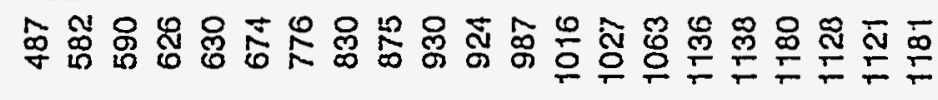 \\
\hline 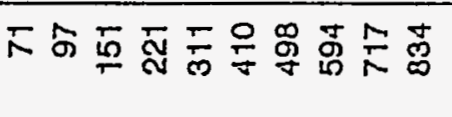 & & 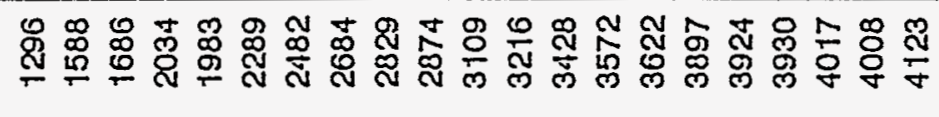 \\
\hline 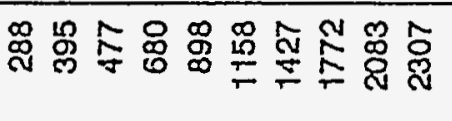 & & 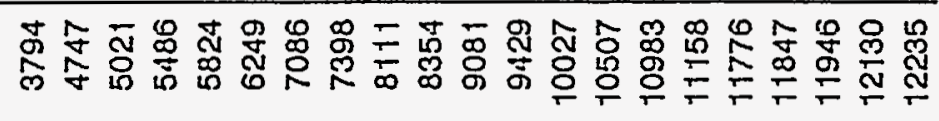 \\
\hline 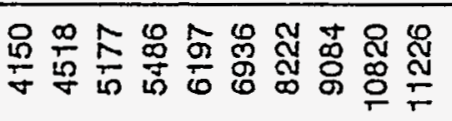 & & 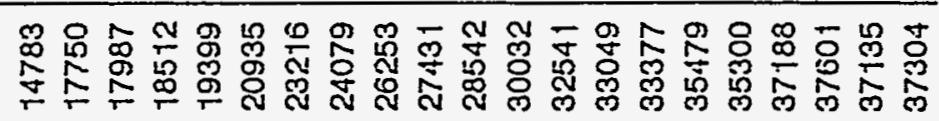 \\
\hline
\end{tabular}

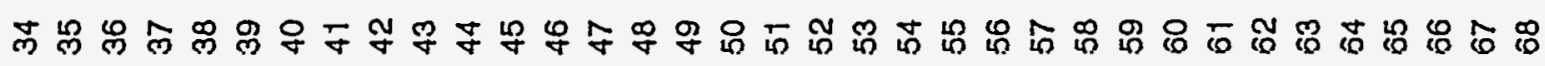




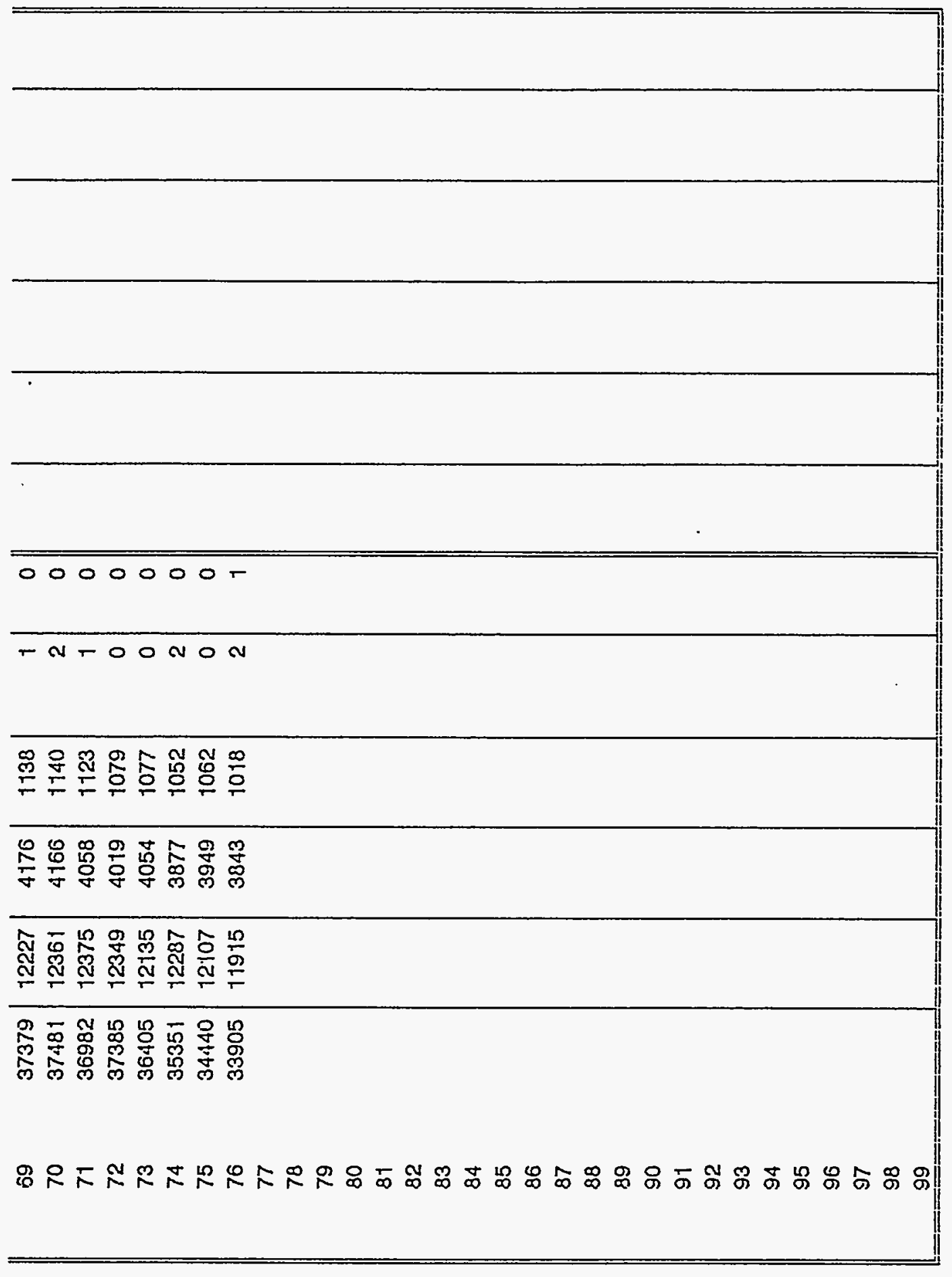


THIRD TEST SERIES

Counter overload (uppe

Counter overload (uppe

Lowered Lid isealed up

If Raised Lid (upper)

Upper Chamber - 


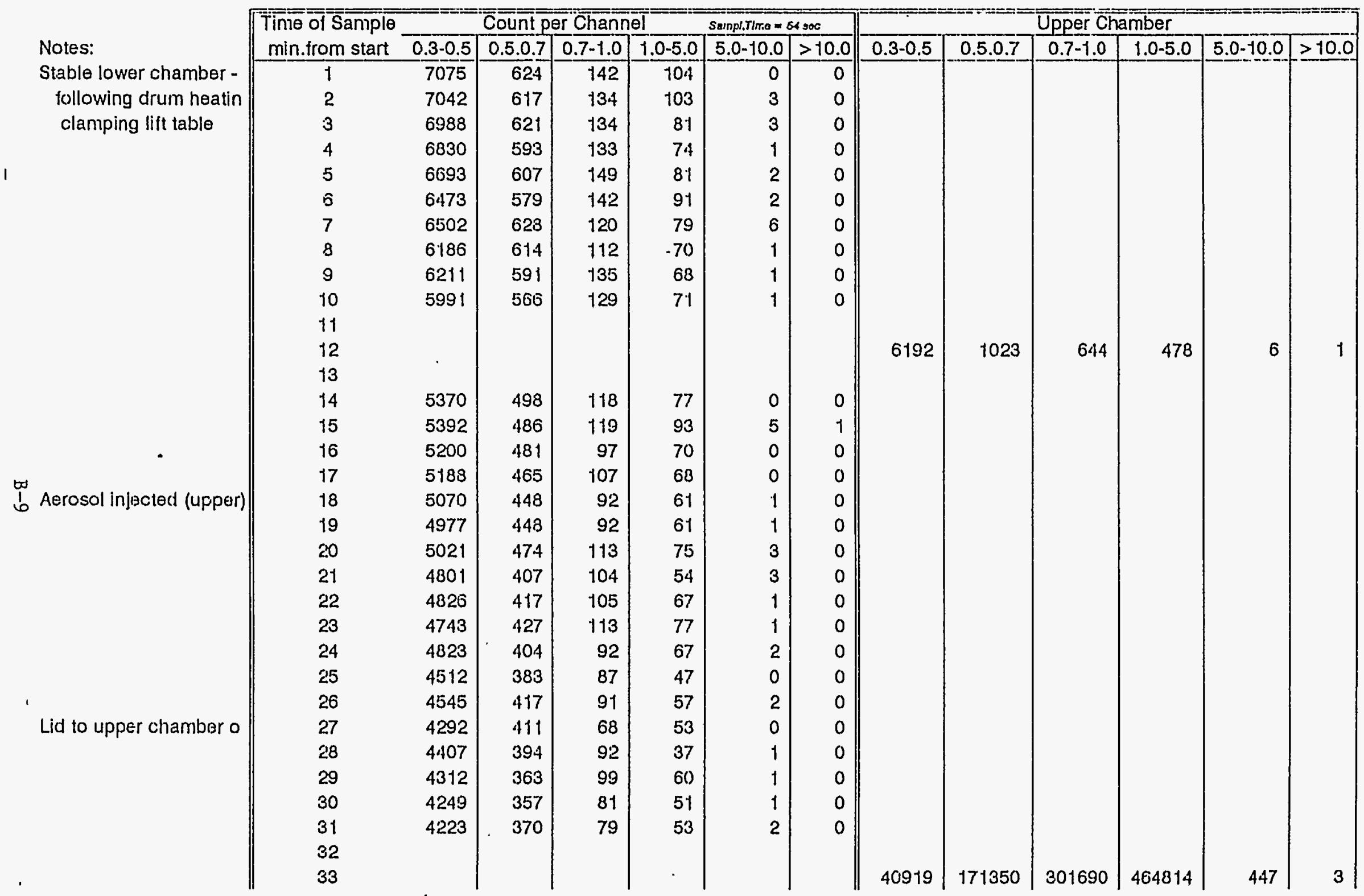


THIRD TEST SERIES

\begin{tabular}{|c|c|c|c|c|c|c|c|c|c|c|c|c|}
\hline . & 69 & 5651 & 1617 & 511 & 148 & 4 & 0 & & & & & \\
\hline & 70 & 5473 & 1624 & 523 & 184 & 5 & 0 & & & & & \\
\hline & 71 & 5743 & 1685 & 506 & 154 & 10 & 2 & & & & & \\
\hline Lowered Lid (sealed up & 72 & 5344 & 1607 & 485 & 154 & 5 & 0 & & & & & \\
\hline & 73 & 5264 & 1486 & 435 & 147 & 4 & 0 & & & & & \\
\hline & 74 & 5194 & 1505 & 466 & 128 & 2 & 1 & & & & & \\
\hline & 75 & 5181 & 1558 & 468 & 202 & 6 & 0 & & & & & \\
\hline & 76 & 5417 & 1595 & 475 & 151 & 6 & 1 & & & & & \\
\hline & 77 & 5116 & 1575 & 492 & 137 & 3 & 0 & & & & & \\
\hline & 78 & 5051 & 1563 & 510 & 166 & 1 & 1 & & & & & \\
\hline & 79 & 5252 & 1626 & 466 & 151 & 3 & 1 & & & & & \\
\hline & 80 & 5148 & 1730 & 470 & 138 & 0 & 1 & & & & & \\
\hline . & 81 & 5358 & 1715 & 485 & 139 & 4 & 0 & & & & & \\
\hline & 82 & 5233 & 1669 & 535 & 126 & 1 & 0 & & & & & \\
\hline & 83 & 5505 & 1728 & 542 & 114 & 0 & 1 & & & & & \\
\hline & 84 & 5306 & 1774 & 560 & 158 & 2 & 0 & & & & & \\
\hline & 85 & 5425 & 1706 & 518 & 138 & 1 & 0 & & & & & \\
\hline & 86 & 5472 & 1795 & 501 & 148 & 2 & 0 & & & & & \\
\hline & 87 & 5456 & 1755 & 541 & 132 & 0 & 0 & & & & & \\
\hline$\vdots$ & 88 & 5337 & 1756 & 491 & 141 & 2 & 0 & & & & & \\
\hline & 89 & 5343 & 1752 & 515 & 117 & 3 & 0 & & & & & \\
\hline & 90 & 5223 & 1704 & 533 & 129 & 1 & 0 & & & & & \\
\hline Lid closed (upper soale & 91 & 5233 & 1736 & 487 & 138 & 3 & 0 & & & & & \\
\hline & 92 & 5230 & 1700 & 491 & 137 & 1 & 0 & & & & & \\
\hline & 93 & 5080 & 1688 & 539 & 112 & 2 & 0 & & & & & \\
\hline & 94 & 5176 & 1760 & 492 & 127 & 2 & 0 & & & & & \\
\hline & 95 & 5064 & 1679 & 514 & 115 & 0 & 0 & & & & & \\
\hline & 96 & 4973 & 1080 & 513 & 103 & 0 & 0 & & & & & \\
\hline 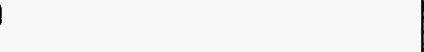 & 97 & 5145 & 1720 & 506 & 111 & 2 & 1 & & & & & \\
\hline & $\begin{array}{l}98 \\
99\end{array}$ & 5098 & 1759 & 457 & 107 & 0 & 0 & & & & & \\
\hline & 100 & & & & & & & & 88 & 10 & 7 & 9 \\
\hline & 101 & & & & & & & & & 614 & & 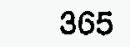 \\
\hline & 102 & & & & & & & 20488 & $121460^{\circ}$ & 272570 & 587366 & 379 \\
\hline
\end{tabular}

